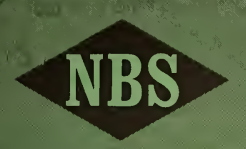

\title{
TECHNICAL
}

NOTE

426

\section{Analytical Mass \\ Spectrometry Section:}

Summary of Activities

July 1966 to June 1967

U.S. DEPARTMENT OF COMMERCE

National Bureau of Standards 


\section{THE NATIONAL BUREAU OF STANDARDS}

The National Bureau of Standards ${ }^{I}$ provides measurement and technical information services essential to the efficiency and effectiveness of the work of the Nation's scientists and engineers. The Bureau serves also as a focal point in the Federal Government for assuring maximum application of the physical and engineering sciences to the advancement of technology in industry and commerce. To accomplish this mission, the Bureau is organized into three institutes covering broad program areas of research and services:

THE INSTITUTE FOR BASIC STANDARDS . . . provides the central basis within the United States for a complete and consistent system of physical measurements, coordinates that system with the measurement systems of other nations, and furnishes essential services leading to accurate and uniform physical measurements throughout the Nation's scientific community, industry, and commerce. This Institute comprises a series of divisions, each serving a classical subject matter area:

-Applied Mathematics-Electricity-Metrology-Mechanics-Heat-Atomic Physics-Physical Chemistry-Radiation Physics-Laboratory Astrophysics ${ }^{2}$ - Radio Standards Laboratory, ${ }^{2}$ which includes Radio Standards Physics and Radio Standards Engineering-Office of Standard Reference Data.

THE INSTITUTE FOR MATERIALS RESEARCH . . . conducts materials research and provides associated materials services including mainly reference materials and data on the properties of materials. Beyond its direct interest to the Nation's scientists and engineers, this Institute yields services which are essential to the advancement of technology in industry and commerce. This Institute is organized primarily by technical fields:

-Analytical Chemistry-Metallurgy-Reactor Radiations-Polymers-Inorganic Materials-Cryogenics ${ }^{2}-$ Office of Standard Reference Materials.

THE INSTITUTE FOR APPLIED TECHNOLOGY ... provides technical services to promote the use of available technology and to facilitate technological innovation in industry and government. The principal elements of this Institute are:

- Building Research-Electronic Instrumentation-Technical Analysis-Center for Computer Sciences and Technology-Textile and Apparel Technology Center-Office of Weights and Measures - Office of Engineering Standards Services-Office of Invention and Innovation-Office of Vehicle Systems Research-Clearinghouse for Federal Scientific and Technical Information ${ }^{3}$-Materials Evaluation Laboratory-NBS/GSA Testing Laboratory.

\footnotetext{
${ }^{1}$ Headquarters and Laboratories at Gaithersburg, Maryland, unless otherwise noted; mailing address Washington, D. C., 20234.

${ }^{2}$ Located at Boulder, Colorado, 80302.

${ }^{3}$ Located at 5285 Port Royal Road, Springfield, Virginia 22151.
} 


\title{
NBS TECHNICAL NOTE 426 \\ ISSUED SEPTEMBER 15, 1967
}

\author{
Analytical Mass \\ Spectrometry Section:
}

Summary of Activities

July 1966 to June 1967

Edited by William R. Shields

Analytical Mass Spectrometry Section
Analytical Chemistry Division
Institute for Materials Research

NBS Technical Notes are designed to supplement the Bureau's regular publications program. They provide a means for making available scientific data that are of transient or limited interest. Technical Notes may be listed or referred to in the open literature.

For sale by the Superintendent of Documents, U.S. Government Printing Office Washington, D.C., 20402 - Price 40 cents 
The Analytical Chemistry Division was established as a separate division at the National Bureau of Standards on September 1, 1963, and became part of the Institute for Materials Research in the February 1, 1964, reorganization. It consists at present of nine sections and about 100 technical personnel encompassing some 45 different analytical competences from activation analysis and atomic absorption to vacuum fusion and $\mathrm{X}$-ray spectroscopy. These competences, and in turn the sections which they comprise, are charged with research at the forefront of analysis as well as awareness of the practical sample, be it standard reference material or service analysis. In addition it is their responsibility to inform others of their efforts.

Formal publication in scientific periodicals is highly important. In addition, however, it has been our experience that informal, annual summaries of progress describing efforts of the past year can be very valuable in disseminating information. At the National Bureau of Standards such publications fit logically into the category of a Technical Note. In 1967 we plan to issue these summaries for all of our sections. The following is the second annual report on progress of the Analytical Mass Spectrometry Section.

W. Wayne Meinke, Chief Analytical Chemistry Division 
The basic function of the Analytical Mass Spectrometry Section is to establish high accuracy absolute isotopic ratio standards. To this end the section is concerned with developing instrumentation and devising analytical techniques which will improve the precision of isotope ratio measurements; and at the same time it has the responsibility of developing the chemical procedures necessary for the preparation of the calibration standards necessary to convert the analytical precision statement to an accuracy statement.

This Technical Note has been written in an entirely different vein than Technical Note 277. The intent of the first Technical Note (277) was to define our position after 8 years of effort and is truly more of a cook book or operating manual than anything else. This Technical Note is intended as a summary of our effort for the fiscal year of 1967 .

There have been more major changes during the past year than in all the previous history of the section. The section now has its own chemists and chemistry laboratories, and has moved in its entirety to the new facilities at Gaithersburg. It is to the credit of the group that the section has doubled in personnel, moved twenty miles, acquired the space and equipped two chemistry laboratories, built two mass spectrometers, and at the same time managed to do most of its normal work load all within the past year.

William R. Shields, Chief

Analytical Mass Spectrometry Section 
1. INSTRUMENTATION.

A. Introduction . . . . . . . . . . . . . . . . 1

B. Facilities . . . . . . . . . . . . . . . I

C. Research Activities. . . . . . . . . . . . . . 2

1. Multi-stage Mass Spectrometer. . . . . . . . 2

2. High Vacuum Beam Valve . . . . . . . . . . 2

3. Z Focussing Source . . . . . . . . . . . . 7

4. Redesigned Collector . . . . . . . . 7

5. Filament Degas Chamber and Controls. . . . . 11

6. Sample Drying. . . . . . . . . . . . . 11

D. Assistance Activities. . . . . . . . . . 15

2. CHEMISTRY. . . . . . . . . . . . . . 16

A. Introduction . . . . . . . . . . . . . . 16

B. Facilities. . . . . . . . . . . . 18

1. Stable Isotopic Chemical Laboratory. . . . . 18

2. Radioactive Isotopic Chemical Laboratory . . 20

3. Balance Room .. . . . . . . . . . . 20

Instrument Room...............

D. Chromium . . . . . . . . . . . . . . . . . 27

E. Fluorspar. . . . . . . . . . . . . . . . 29

F. Lead . . . . . . . . . . . . . . . 30

1. Lead Minerals. . . . . . . . . . . . . 31

2. Preparation of Lead from Mineral Samples . . 32

3. Archaeological Samples... . . . . . . 33

G. Plutonium. . . . . . . . . . . . . 34

1. Chemical Standard. . . . . . . . . . 34

2. Isotopic Standard. . . . . . . . . . 34

3. MASS SPECTROMETRY. . . . . . . . . . . . 35

A. Boron. . . . . . . . . . . . . . . 35

B. Chromium . . . . . . . . . . . . . . 41

C. Lead .. . . . . . . . . . . . . . . . . 41

D. Plutonium. . . . . . . . . . . . . . 44

E. Rubidium . . . . . . . . . . . . . . . . 44

F. Uranium. . . . . . . . . . . . . . . 45

4. PERSONNEL AND ACTIVItTIES. . . . . . . . . . . . 46

A. Personnel Listing. . . . . . . . . . . . . 46

B. Publications.............. . . 46

C. Talks. . . . . . . . . . . . . . . 50

D. Committee Activities . . . . . . . . . . 51

5. REFERENCES . . . . . . . . . . . . . 52 
1. Main instrument laboratory ... . . . . . . . 3

2. Flight path of two-stage instrument. . . . . . . 4

3. Two-stage instrument . . . . . . . . . . . 5

4. Cross section of beam valve. . . . . . . . . 6

5. Z lens source assembly . . . . . . . . . . 8

6. Source controls. . . . . . . . . . . . . 9

7. Collector assembly (standard). . . . . . . . . 10

8. Filament degas chamber and controls. . . . . . . 12

9. Schematic of filament degas controls . . . . . . . 13

10. Sample dryer arrangement in hood . . . . . . . 14

11. Sample dryer arrangement on table... . . . . 15

12. and

13. Stable isotopic chemistry laboratory . . . . . 19

14. and

15. Radioactive isotopic chemistry laboratory. . . . 21

16. Balance room . . . . . . . . . . . . . 22

17. Instrument room. . . . . . . . . . . . 22

LIST OF TABLES

TABLE NO.

1. Boron recovery by chloroform-2-ethyl-1,3-hexanediol extraction procedure ............ . 26

2. Determination of possible boron isotopic fractionation. . . . . . . . . . . 27

3. Calculated atomic weights for "normal" leads . . 32

4. Organic extraction of ANL-II without control of excess $\mathrm{SO}_{2}$ water............ . . 36

5. Organic extraction of ANL-II with known volume of $\mathrm{SO}_{2}$ water added before extraction into 2-ethyl-1,3-hexanediol . . . . . . . . . 37

6. Organic extraction of ANL-II with control of excess $\mathrm{SO}_{2}$ water by digesting solution uncovered and at temperature of $80^{\circ}$ to $85^{\circ} \mathrm{C}$. . 38

7. Comparison of $95 \%$ confidence limits ( $t \sigma)$ of best data on replicate lead isotope analyses by various methods. 
ANALYTICAL MASS SPECTROMETRY SECTION: SUMMARY OF ACTIVITIES JULY 1966 TO JUNE 1967

Edited by William R. Shields

\section{ABSTRACT}

This report describes the advances in instrumentation and the research activities of the Analytical Mass Spectrometry Section during the period July 1966 to June 1967.

Advances in instrumentation include the construction of a multi-stage mass spectrometer, a high vacuum beam valve, a $\mathrm{Z}$ focussing lens, a re-designed collector, a filament degas chamber, and new equipment for sample drying. The new facilities at Gaithersburg are described.

Elements studied during this period include: $\mathrm{B}, \mathrm{Cr}, \mathrm{Pb}$, $\mathrm{Rb}, \mathrm{U}$, and $\mathrm{Pu}$. Chemical procedures are given for $\mathrm{B}, \mathrm{Cr}, \mathrm{Pb}$, and $\mathrm{Pu}$; mass spectrometric procedures are given for $\mathrm{B}, \mathrm{Cr}, \mathrm{Pb}$, $\mathrm{Pu}, \mathrm{Rb}$, and $\mathrm{U}$.

Key words: Mass spectrometry, instrumentation, procedures, isotopic analyses. 


\section{A. Introduction}

The primary analytical tool of this laboratory is the mass spectrometer and this section of the report will deal with the changes and/or improvements that have taken place within the past year on the spectrometers. There is, of course, a large amount of ancillary instrumentation used by the chemists and mass spectroscopists, and they will discuss these items in their section of this report.

\section{B. Facilities}

The Analytical Mass Spectrometry Section was moved to the new Gaithersburg site during September and October 1966. Preparation of mass spectrometers (5) [ref. 1, p. 1] and other apparatus for the move to the new laboratory facility was started 2 weeks before arrival of the packers. Disassembly of each spectrometer included removal of the analyzer tube, pumping system, electronics, and utilities. Diffusion pumps and components of the analyzer assembly were cleaned and, where practical, sealed in plastic bags. The empty electronic console was separated from the magnet support frame and divided into two smaller units to facilitate handling. The magnet and frame, with appropriate preparations, were moved as a unit. The components of the analyzer assembly were moved by automobile or station wagon. The bellows in the pumping arm of a source housing was ruptured and was the only apparatus to suffer major damage during the move.

The electronic console and magnet frame were mated, leveled, and electronic panels mounted. Reassembly of the flight tube and pumping system was not started until utilities to each spectrometer were completed. The first spectrometer was operational two weeks after the equipment arrived at the new site, and the remaining spectrometers were reassembled and operational at the rate of one per week. 
The mass spectrometer laboratory consists of nine modules divided as follows: (1) four modules for the main instrument bay (figure 1); (2) one module divided into two rooms, one room for source, collector, and filament cleaning and assembly, the second room for sample handling. The cleaning room is equipped with one hood. The sample handing room contains two hoods, one for low level radioactive materials and one for high level radioactive materials; (3) two modules for a threestage mass spectrometer; (4) two modules for a shop to fabricate electronics.

C. Research Activities

1. Multi-stage Mass Spectrometer

The first two stages of a three stage mass spectrometer have been designed and constructed and are now operational. The optical path chosen is an off axis extended flight path "S" configuration (figures 2 and 3 ).

2. High Vacuum Beam Valve

The need for high vacuum operation, with large volume vacuum envelopes and rapid recovery time, created a demand for an effective beam valve, i.e. in the flight tube itself. The resultant valve is shown in figure 4 . The valve is still under test with major emphasis on the beam valve seal material. The thruput opening is $.375 \mathrm{x} .750$ with the seal being cut back. .031 from the opening. The initial material used for the seal was teflon; this material, however, peels when subjected to rotary motion under pressure. It was discovered that several shreds protruding into the thruput opening were sufficient to virtually shut off the ion beam, this due to the electrostatic charging of the teflon. Preliminary steps are being taken to test a poly resin compound which is carbon impregnated; the carbon should provide the desired electrical conducting properties. 


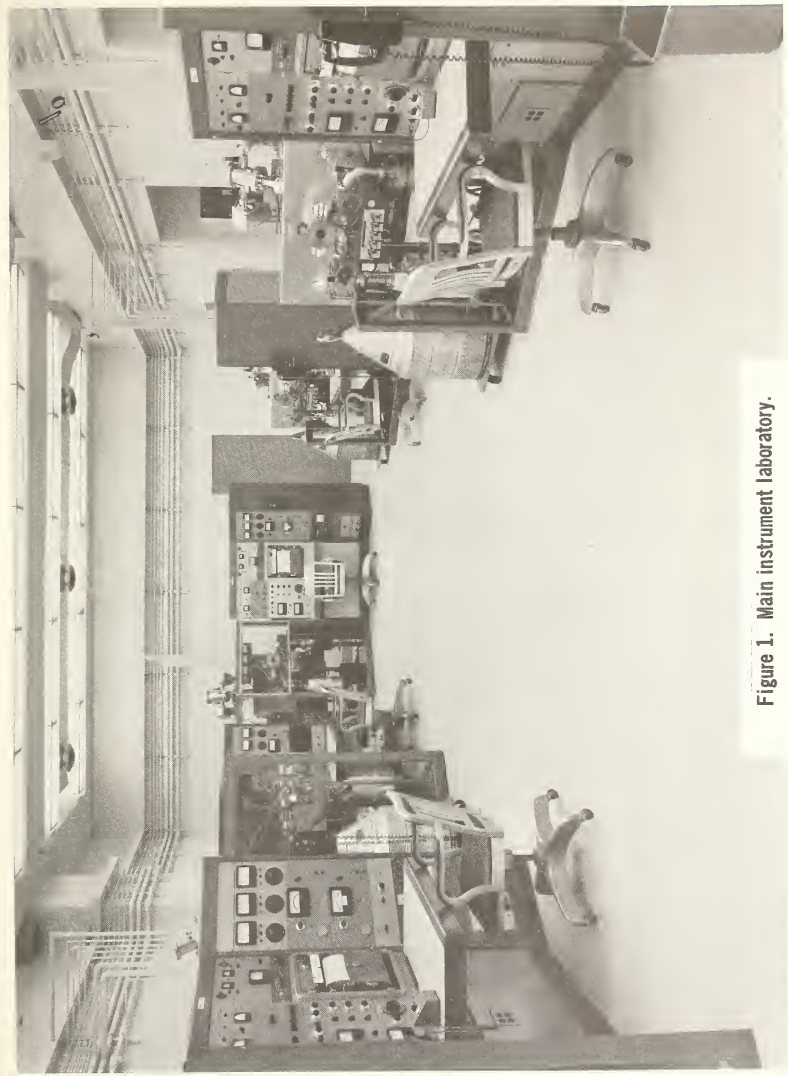




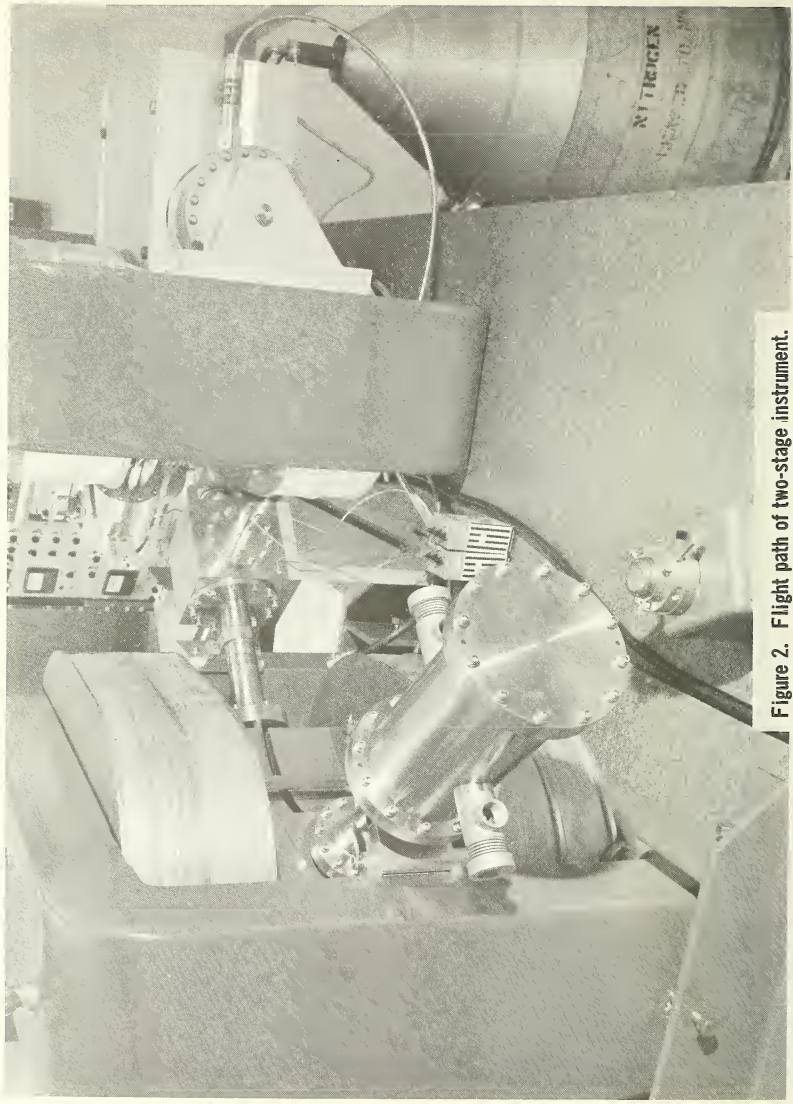




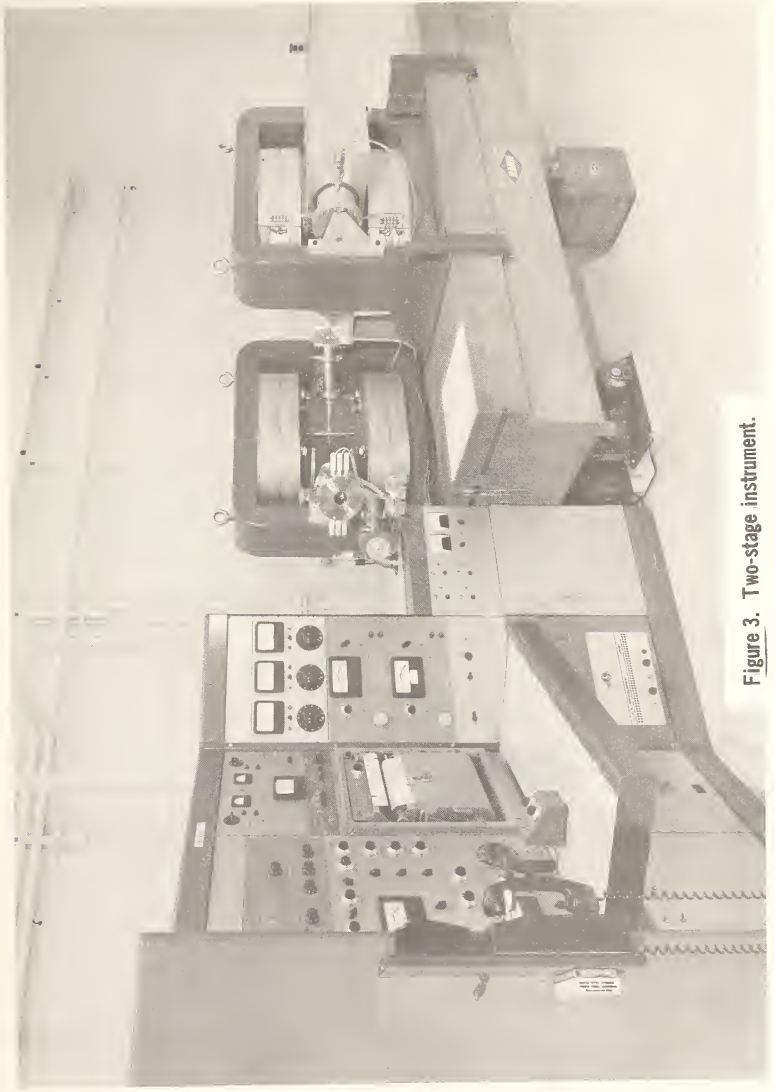




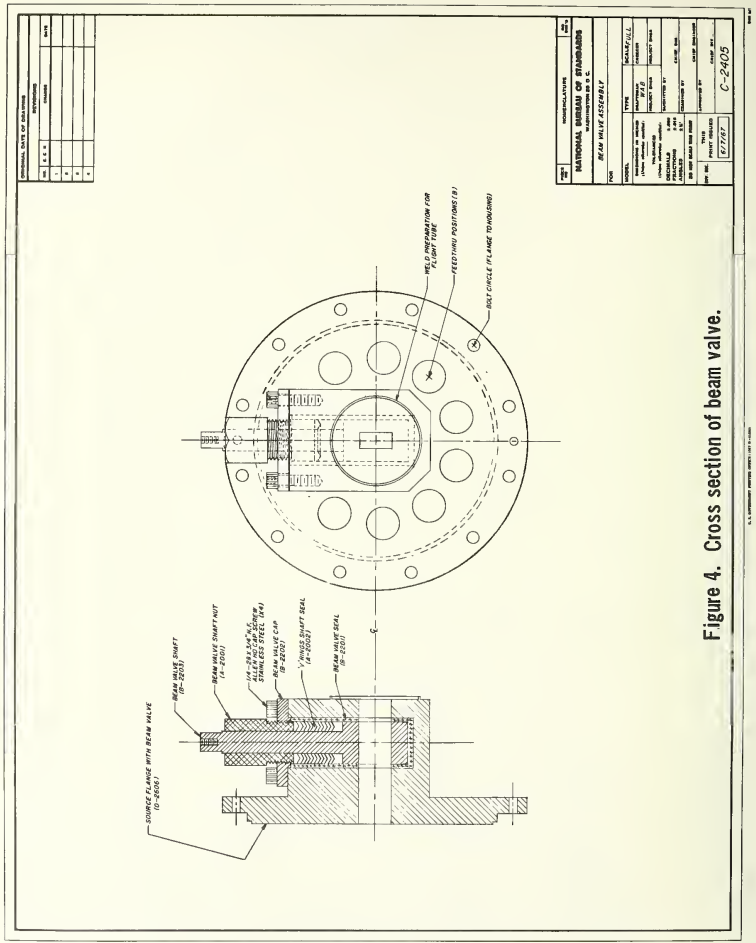




\section{Z Focussing Source}

The dispersion in the $\mathrm{Z}$ axis of the ion beam had to be reduced in order to maintain reasonable transmission efficiency in the multi-stage instrument. A source containing elements for $\mathrm{Z}$ focussing has been developed, tested, and put into use. The testing of this source was done on one of the single stage 12 " machines and worked so well that all of the instruments have now been converted to include $\mathrm{Z}$ focussing. Figure 5 is a schematic of the new source that is currently being used on all our instruments. Figure 6 is a schematic of the control panel necessary to focus the source. We designed a number of panels before we settled on this circuit. The idea of a single circuit for focussing on all instruments 6", 12", multi-stage, requires that the circuit have a great number of degrees of freedom.

This source increases the transmission efficiency of the single stage 12" instruments by a factor of from 3 to 4 and thus allows us to control the filament biases over a much larger range, and for those elements where we had fairly low ionization efficiency we now have a stronger signal and greatly improved precision.

4. Redesigned Collector

The collector has been redesigned to include the same slot type mount as the new source (figure 7). This type mount allows for a much higher accuracy in the alignment of the slits, and the entire operation, fabrication, installation, and alignment, is done without any jigs or fixtures. When the tube is placed horizontally on a surface plate the slot for the collector can be set horizontal with almost any dial gage, the slot for the source mount will be vertical at this time but by clamping a precision square in the slot with a gage block you have a horizontal reference surface. The diameter of the collector mount was also increased to allow greater pumping speed to the collector housing. 


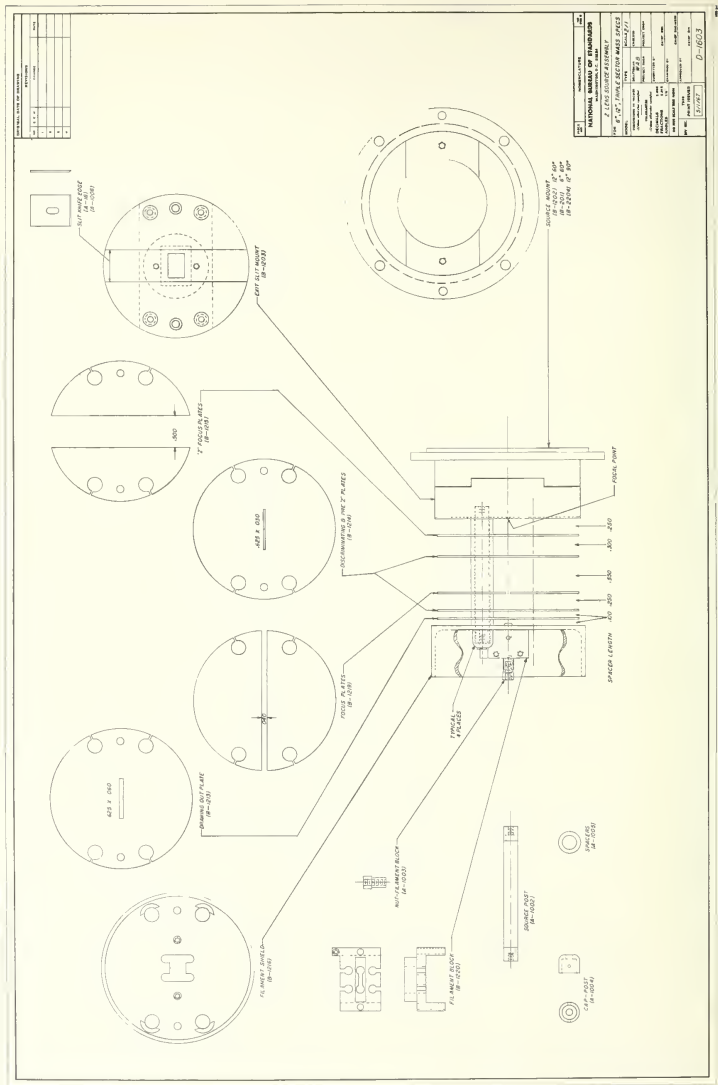

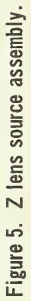




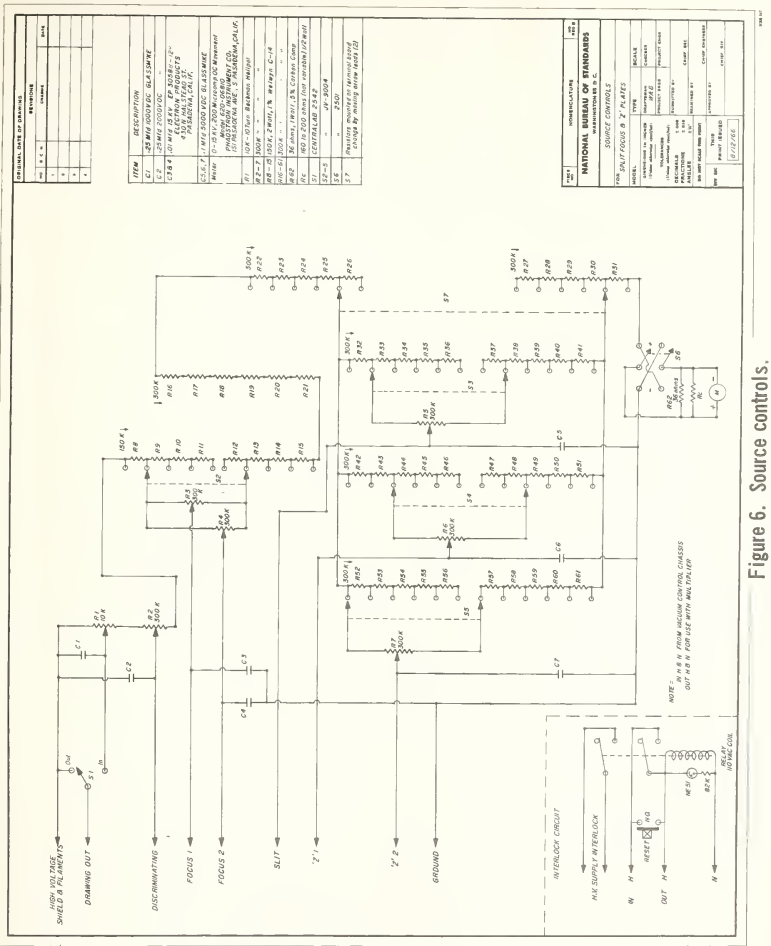




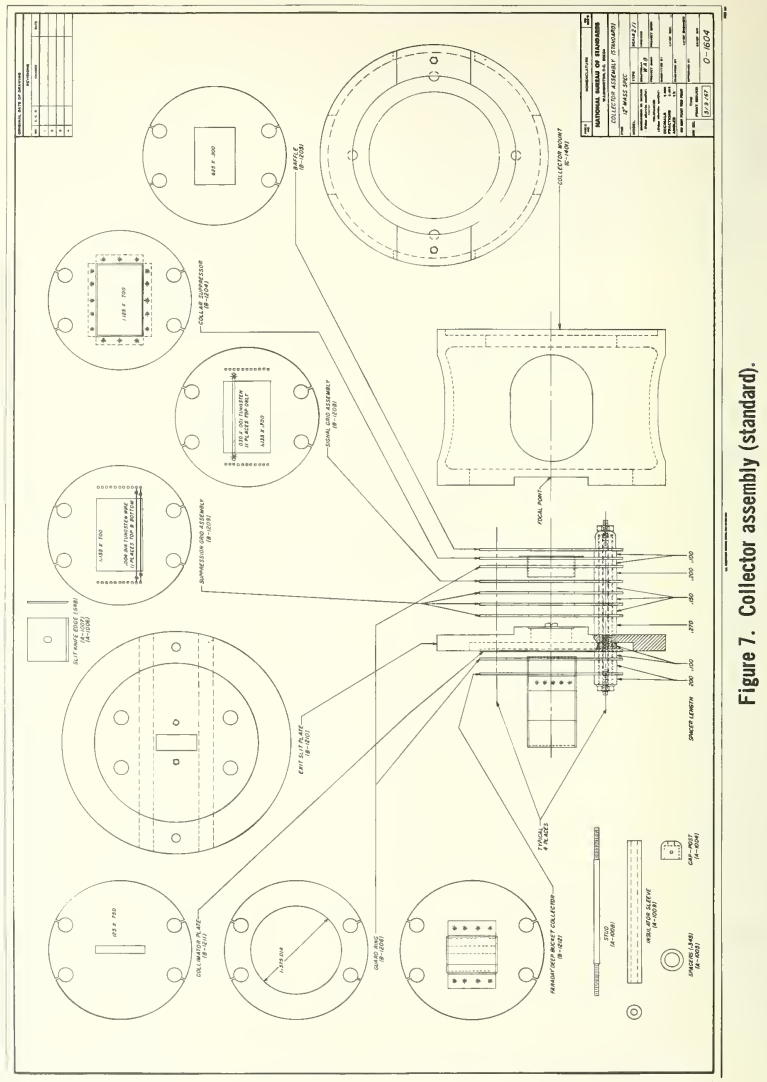


5. Filament Degas Chamber and Controls

The requirement for sample filaments to be free of alkali and alkaline earth contaminants lead to the construction of a vacuum chamber with provisions for thermally ionizing and collecting the ions of these materials from six filaments simultaneously (figure 8 ). The filaments are maintained at a voltage potential difference of approximately $+180 \mathrm{~V}$ DC with respect to a plate located $3 / 4$ " above the filaments. When the filaments are heated, by an alternating current, the ions produced on the filament surfaces are drawn off to the above plate. The filament heating current is controlled by a variable transformer with a current meter on the output side. This control is necessary for handing different filament materials as well as different numbers of filaments. By means of the measuring circuit the ion current may be observed and the cleaning process maintained until the desired minimum current is reached. Two possible situations are:

(1) uniformity in contaminant level or (2) complete reduction of contaminant.

The vacuum system incorporates a mechanical pump with thermocouple gauge and a 100 liter/ion pump. After the starting pressure for the ion pump is reached the mechanical pump is valved off by a l" ball valve.

All controls, except ion pump, are indicated in figure 9 .

6. Sample Drying

Samples are loaded on the filaments in solution and must be dried and/or taken to a metallic state for use in the mass spectrometer. The use of radioactive materials require that this be done in a hood and that the controls be outside the hood (figure 10). The use of a single filament with nonradioactive materials may be handled on the table top (figure 11). Both of these units are composed of a low voltage transformer with a current control to reach and maintain a desired temperature thru the filament being loaded. External drying is accomplished by the use of a 250 watt heat lamp. 


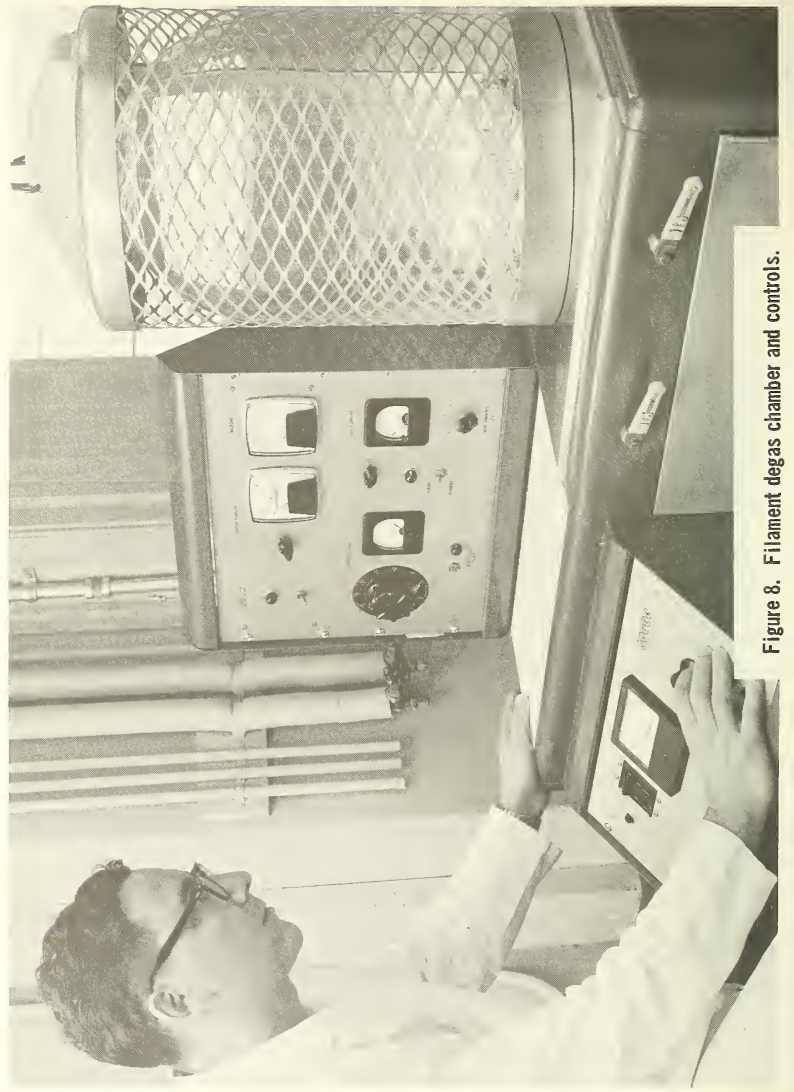




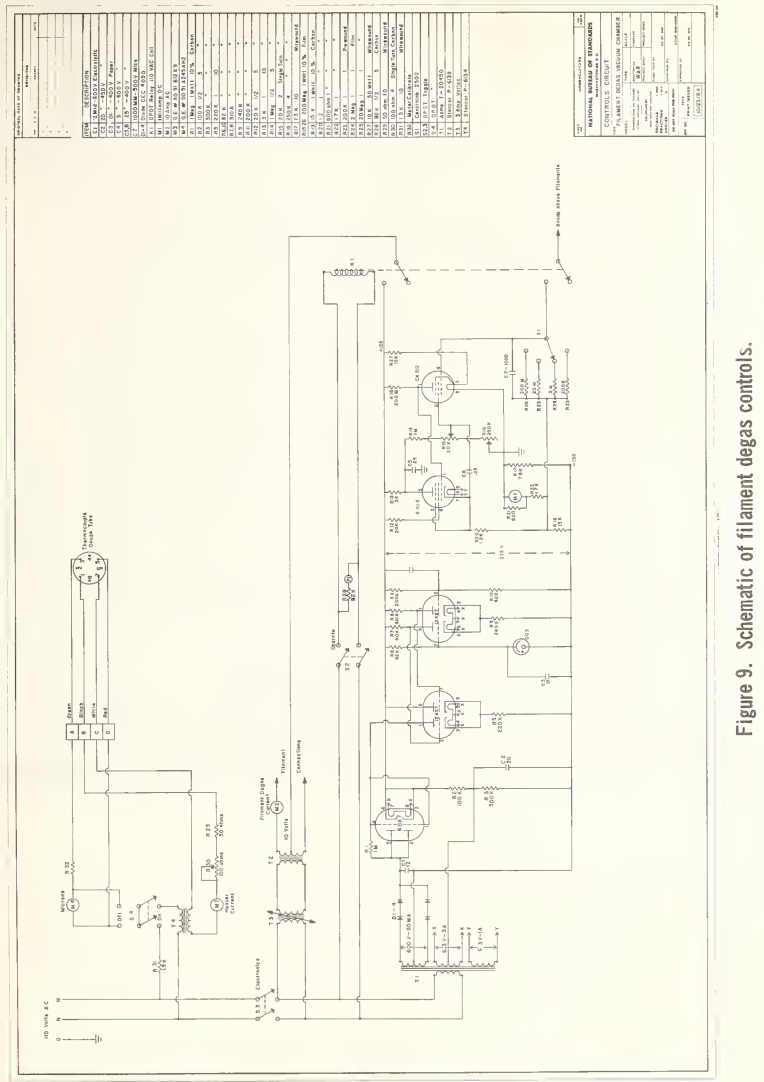




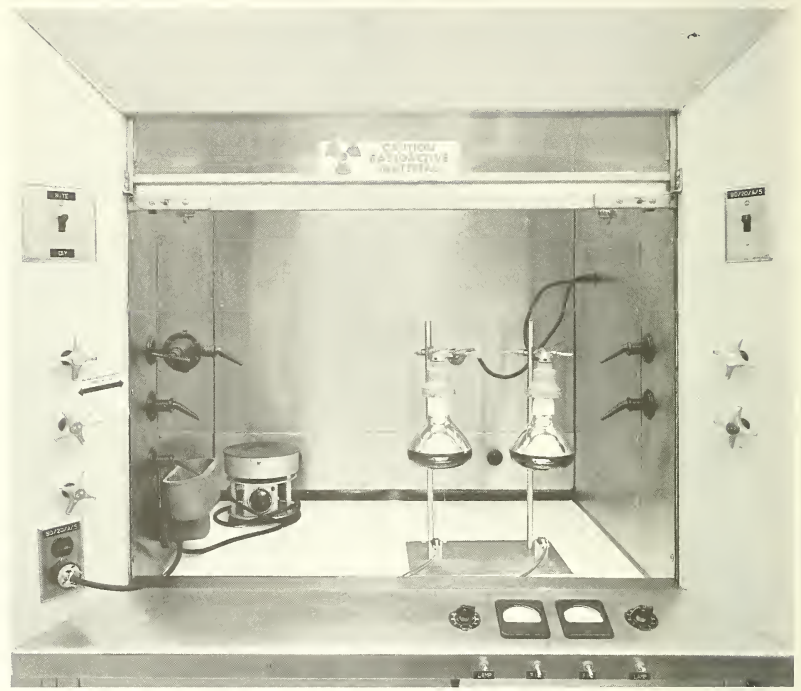

Figure 10. Sample dryer arrangement in hood. 


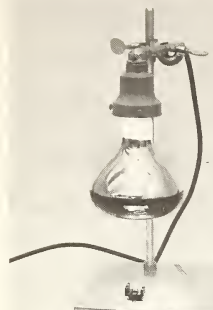

Figure 11. Sample dryer arrangement on table.

D. Assistance Activities

During the past year a large number of instrument drawings and electronic schematics were furnished to other laboratories interested in constructing or modifying mass spectrometers similar to those used in this laboratory. Electronic controls have been designed and fabricated for use in other areas of the NBS. Two Leeds and Northrup Speedomax $W$ recorders were rebuilt to provide expanded scale measuring [ref. 1, pp. Il16]. These instruments were modified by request of:

(1) Oberlin College, Oberlin, Ohio; (2) Kansas State University, Manhattan, Kansas. Both instruments are in operation and the concerned individuals report much higher precision than that obtained prior to the modification.

(W. A. Bowman, III) 
A. Introduction

This group was started with the transfer of Thomas J. Murphy from the Microchemical Analysis Section in May of last year. Lawrence A. Machlan joined us in July after transfer from the Analytical Coordination Chemistry Section, and Keith M. Sappenfield joined us in October also after transfer from the Analytical Coordination Chemistry Section. The personnel of this group have over 50 years combined experience in analytical chemistry, most of which is in the high precision - high accuracy field. Mr. Machlan and Mr. Murphy have been engaged for a number of years in the programs of this section, so the transfers had the effect of giving this section its own chemical competence without having it spread thru the other sections of the division.

There are three projects within the group. The first project deals with the determination of atomic weights by direct measure of their absolute isotopic concentrations. There are three possible sources of error in atomic weights determined by this method: (1) errors due to nuclidic mass measurements, (2) errors in the measurement of isotopic composition, and (3) undetected natural variations in isotopic composition. The nuclidic masses are now known to better than one part in a million (with few exceptions), so errors due to this source are negligible. The measurement of isotopic composition, however, is not in such satisfactory condition. Bias due to mass discrimination causes errors which can be corrected only by the use of standards prepared from separated isotopes. The accurate preparation of these standards requires that the separated isotopes be mixed with an accuracy of $\pm 0.01 \%$. The major effort of this project is toward the development of precise and accurate analytical procedures and proven stoichiometric forms so that the isotopic standards can be prepared with the necessary accuracy. Since most of the 
classical methods of analysis have not been proven to better than $0.1 \%$, new methods must be developed. These methods must utilize only small samples ( $1-5 \mathrm{meq}$.) since the amounts of separated isotopes available are usually small. The methods developed to date have included such analytical disciplines as constant current coulometry and amperometry as with chlorine [2], bromine [3], and chromium [4]; a combination of electrodeposition and spectrophotometry as in the case of copper [5]; and gravimetry as in the case of magnesium [6]. In the future it is expected that other analytical disciplines will also be used.

To define the error due to natural variations in isotopic composition, it is necessary to establish the constancy of isotopic composition in nature or to establish limits of variability by measuring the isotopic composition of a number of mineral samples of different origin. These mineral samples must be processed chemically and converted to a form suitable for mass spectrometric analysis. This entails processing and measuring a large number of mineral samples; for example over 100 minerals in the case of copper [7] and 60 minerals in the case of magnesium [8].

This has been a highly successful program. To date the atomic weights of six elements have been re-determined. They are silver, chlorine, bromine, copper, chromium, and magnesium. In 1965 the International Commission on Atomic Weights accepted our values for silver, chlorine, copper, and bromine as the recommended atomic weights [9]. Chromium and magnesium will be considered this year.

The second project deals with nuclear isotopic standards for mass spectrometry. We are responsible for the preparation of precise and accurate isotopic composition standards from separated isotopes so that the absolute abundance ratios of standard materials of vital interest to the nuclear industry can be determined. There are certain parallels between this program and the atomic weights program in that both require 
the development of precise and accurate methods of analysis so that isotopic standards can be prepared, but there is the added difficulty in this program of the high radio-activity of most of the isotopes. Accurate standards have been prepared for uranium and ten uranium isotopic standards have been certified. The preparation of accurate calibration standards for plutonium and boron are planned for the near future.

The third project has to do with trace characterization by isotopic dilution. This section has not been active in this field in the past, but we plan to start work later this fall. The initial effort will be directed toward the quantitative preparation of stock "spike" solutions of separated isotopes and the development of chemical techniques to extract and purify the elements under study. A major advantage of this technique is that once the isotopic spike has been added, none of the following chemical steps need be quantitative.

B. Facilities

The chemical facilities consist of a double module general purpose laboratory, a single module radioactivity laboratory, a balance room, a double module instrument room shared with Section 310.07 and an office. These facilities have been modified and equipped since July 1966.

1. Stable Isotopic Chemical Laboratory

The stable isotopic chemical laboratory, (figures 12 and 13) is a double module room with two hoods. Equipment includes a controlled potential electro-analyzer for the separation of metals, a constant current coulometric analyzer for precise electrochemical analysis, a quartz still for producing ultrapure water, a high temperature muffle furnace, a tube furnace, pH meters, reagent balances, automatic titrator, and other equipment normally found in a general purpose wet chemical laboratory . 

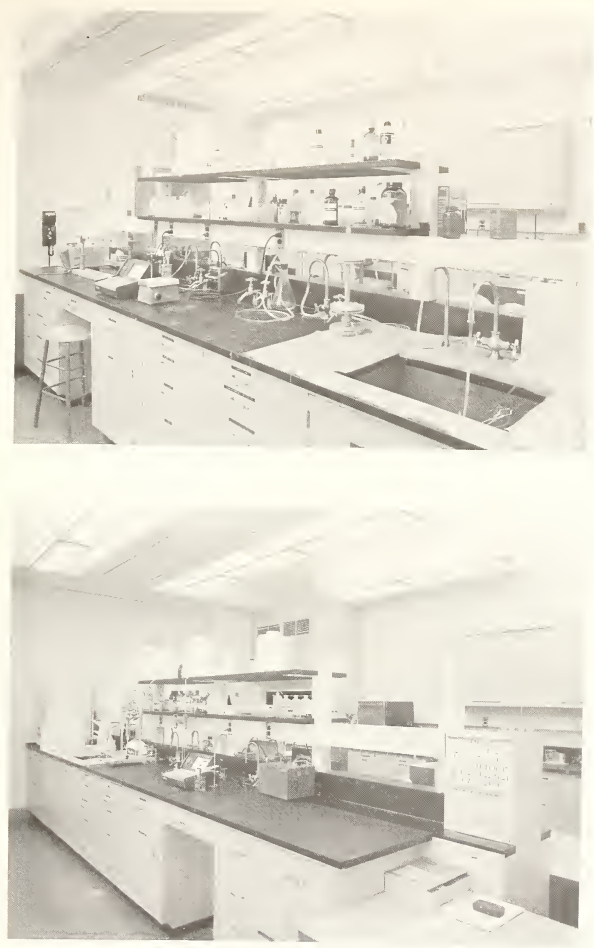

Figures 12 and 13 . Stable isotopic chemistry laboratory. 
2. Radioactive Isotopic Chemical Laboratory

The radioactive isotopic chemical laboratory (figures 14 and 15) has recently been completed. The 2 hoods and the 4 glove boxes were moved from the old NBS site. The responsibility for this radioactivity work was transferred to Section 310.06 in July 1966 with a corresponding change in location for the radioactivity laboratory. In addition to the delay caused by this change, other delays were encountered in coordinating the contractor and NBS plant sections and in problems with dampers, ductwork, motor, and fan. Figure 14 shows a glove box containing a microbalance for precision weighing of radioactive materials and a large hood that will contain a tube furnace for ignition of samples and have space for other uses. Figure 15 shows a fume hood and large glove box for work with solutions of radioactive materials, a glove box with gloves for high activity materials in solid form, and a glove box containing a $200 \mathrm{~g}$ capacity balance that will be used primarily for weighing radioactive solutions. This laboratory has been designed for work with uranium and plutonium at the present time and will be available for use with other radioactive materials in the future.

3. Balance Room

The balance room (figure 16) contains one 200 \& capacity macro-analytical balance, two $100 \mathrm{~g}$ capacity semi-micro balances, and one $20 \mathrm{~g}$ capacity microbalance. These balances have been placed on 700 pound marble tables to minimize vibrations.

4. Instrument Room

The instrument room (figure 17) contains a multipurpose recorder and a photoelectric spectrophotometer. 

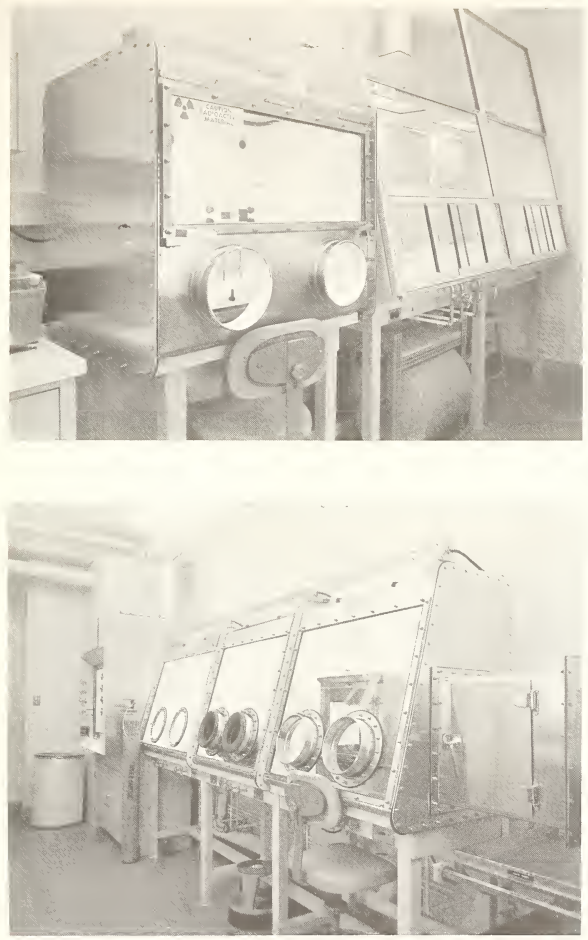

Figures 14 and 15. Radioactive isotopic chemistry laboratory. 


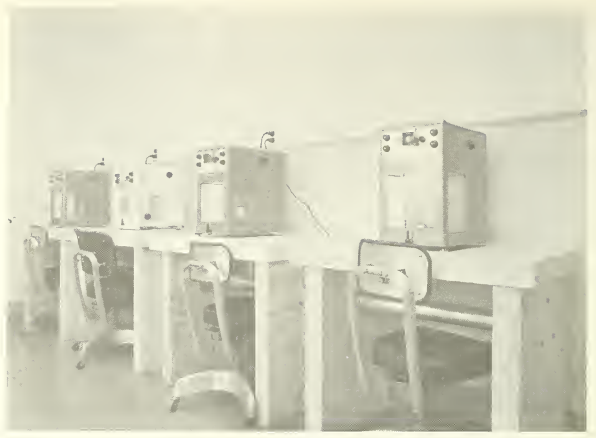

Figure 16. Balance room.

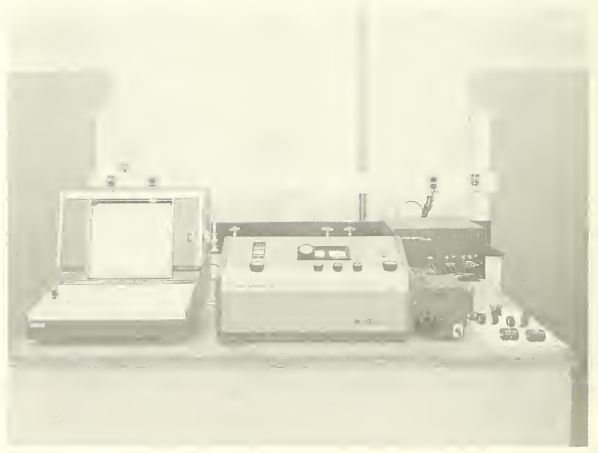

Figure 17. Instrument room. 
C. Boron

The Office of Standard Reference Materials has submitted three materials of "Glass Beads for Neutron Flux Measurements" for the determination of the isotopic composition and the percentage of boron to an accuracy of 0.1 to 0.25 percent of the measurement. The glass beads contain $\mathrm{Al}_{2} \mathrm{O}_{3}, \mathrm{Li}_{2} \mathrm{O}, \mathrm{SiO}_{2}$, and $\mathrm{B}_{2} \mathrm{O}_{3}$ in addition to a different activator (potentially radioactive via neutron absorption) for each glass. The three activators chosen were dysprosium, indium, and cobalt with the boron used in preparing these glasses approximately $93 \%{ }^{10} \mathrm{~B}$.

To determine the isotopic ratio of the boron, it is necessary to separate the boron from the other constituents and obtain it in a solution of $1 \mathrm{mg} B$ per ml with a $\mathrm{Na} / \mathrm{B}$ ratio of 1:1 [ref. 1, p. 67]. One method of determining the percentage of boron is by isotopic dilution. This method was chosen because only a small amount of sample is required, it should give the required accuracy, and after making the dilution it will not be necessary to separate the boron quantitatively from the other constituents.

Two procedures have been used for the separation of boron, one using ion exchange and the other solvent extraction. The Argonne-II (ANL-II) boric acid was used as a workingstandard. All values obtained will be based on the ${ }^{11} \mathrm{~B} /{ }^{10} \mathrm{~B}$ ratio and any boron contamination from reagents would cause a change in this ratio. The reagents were checked for boron content by a boron-curcumin complex photometric method adapted by E. R. Deardorff (Section 310.04) from Hayes and Metcalfe [10]. The boron content of the reagents for the ion exchange separation was found to be less than $0.1 \mu \mathrm{g}$ compared to about $15 \mathrm{mg}$ of $\mathrm{B}$ in the sample size to be taken.

The dysprosium glass was selected as the first glass to be analyzed. When the glass was fused with sodium carbonate, the dysprosium did not dissolve in water but on acidifying it dissolved; however, some of the silicon precipitated. 
Boron was determined in the dysprosium residue by the boroncurcumin complex.

The ion exchange method was adapted from Wolszon, Hayes, and Hill [11] for the separation of boron and silicon. Using an anion exchange column, the boron and silicon, as the borate and silicate ions in a carbonate solution, were absorbed while the lithium and aluminum passes through the column. The boron was eluted with $0.1 \underline{\mathrm{N}} \mathrm{NaOH}$ and the silicon with $1 \underline{\mathrm{N}} \mathrm{NaOH}$. The boron was not fractionated and the recovery was 95 percent.

The sodium was removed from the elute by passing the solution through a cation exchange column. By titrating an aliquot of the elute, the boron concentration was determined and to another aliquot an equivalent amount of $0.1 \mathrm{~N} \mathrm{NaOH}$ was added. The volume of this solution was adjusted to $1 \mathrm{mg} \mathrm{B} / \mathrm{ml}$ of solution and the ${ }^{1{ }^{1} \mathrm{~B} /{ }^{10} \mathrm{~B}}$ ratio determined.

Four plastic ion exchange columns were prepared for the separation of boron and silicon. The columns, $2.5 \mathrm{~cm}$ diameter, were filled to a height of $16 \mathrm{~cm}$ with anion exchange resin ( $A G 1-X 8,200-400$ mesh). The resin was converted to the $\mathrm{OH}$ form by passing $1 \mathrm{~N} \mathrm{NaOH}$ through the column and the excess $\mathrm{NaOH}$ removed from the column with water.

Four plastic ion exchange columns were prepared for the removal of sodium from the elute of the anion exchange column. The columns, $2.5 \mathrm{~cm}$ diameter, were filled to a height of $12 \mathrm{~cm}$ with cation exchange resin ( $A G$ 50-X8, 100-200 mesh) and washed with 1 N HCl. Finally, the column was washed with water to remove the excess $\mathrm{HCl}$.

A $0.3 \mathrm{~g}$ sample of the glass beads, for the determination of the ${ }^{11} \mathrm{~B} /{ }^{10} \mathrm{~B}$ ratio, two $0.15 \mathrm{~g}$ samples of the glass beads, to be used for spiking with natural Argonne II boric acid, and $0.17 \mathrm{~g}$ of Argonne II boric acid were fused with $2 \mathrm{~g} \mathrm{Na}_{2} \mathrm{CO}_{3}$ and the melts dissolved in water. The solutions were filtered and the residues were washed with water. Plastic or quartz ware were used throughout the procedure. 
The residues were washed from the papers and dissolved in $\mathrm{H}_{2} \mathrm{SO}_{4}$. The boron was determined in these solutions by the boron-circumium complex photometric method. The boron in the residues of the samples was 30,3 , and 3 micrograms respectively and the final results were corrected accordingly.

Approximately $0.08 \mathrm{~g}$ of Argonne II boric acid was added to each of the $0.15 \mathrm{~g}$ sample of the beads and all samples were diluted to $150 \mathrm{ml}$ with water. The solutions were passed through the anion exchange columns and washed with $150 \mathrm{ml}$ of water.

The boron was eluted with $400 \mathrm{ml}$ of $0.1 \mathrm{~N} \mathrm{NaOH}$. The elute was evaporated to $25 \mathrm{ml}$, passed through the cation exchange column and the column was washed with $75 \mathrm{ml} \mathrm{H}_{2} \mathrm{O}$.

A $20 \mathrm{ml}$ aliquot out of $100 \mathrm{ml}$ of each solution was titrated with $0.1 \mathrm{~N} \mathrm{NaOH}$ to determine the concentration of boron. To another aliquot of the solution containing approximately .005 $\mathrm{g}$ of boron, $0.1 \mathrm{~N} \mathrm{NaOH}$ was added to give an equivalent amount of sodium. The volume of the solutions

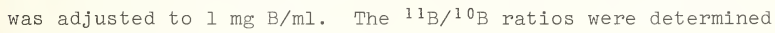
on these solutions. The results were inconclusive.

The above described procedure had the following drawbacks: (1) the conversion of the anion exchange resin to the $\mathrm{OH}$ form was difficult, (2) the necessity of evaporating large volumes of solution increased the possibility of contamination, and (3) the procedure was time consuming; therefore, a recently published extraction method by E. J. Agazzi [12] was investigated. In this method the boron was extracted into a chloroform solution of 2-ethyl-1,3-hexanediol from an acid solution but could not be extracted from an alkaline solution. These facts suggested that the boron could be extracted from the glass in an acid solution and stripped from the organic phase with sodium hydroxide. During the adapting of this method the cobalt glass was given the highest priority, therefore, the method was changed to apply to this glass. 
The sample was fused with sodium carbonate, dissolved in water, made acid with sulfuric acid, and reduced with $\mathrm{SO}_{2}$ water to dissolve the cobalt. After heating to expell most of the $\mathrm{SO}_{2}$, a double extraction was made with chloroform-2-ethyl-1, 3-hexanediol mixture. The organic layer was washed with dilute sulfuric acid and the boron was back extracted into a sodium hydroxide solution. The sodium hydroxide solution was washed with chloroform and then gassed with carbon dioxide. Some examples of the boron recovered are given in table $l$. Since complete recovery is not required as long as the boron isotopes are not fractionated, the organic and aqueous layers were separated with the goal of minimizing contamination. To determine if any fractionation was taking place, a comparison was made of the ${ }^{11} \mathrm{~B} /{ }^{10} \mathrm{~B}$ ratios of one sample not extracted, one sample extracted with one portion of chloroform-2-ethyl-1, 3-hexanediol mixture, the average of several samples extracted with the normal double extraction, and one sample run through the extraction procedure twice. The results in table 2 show that there is not detectable fractionation by this extraction procedure.

Table 1. Boron recovery by chloroform-2-ethyl-1,3-hexanediol extraction procedure.

Sample
1
2
3
4
5
6
7
8

$\%$ B recovered

92

92

97

97

94

94

98

97

Average 95 
Table 2. Determination of possible boron isotopic fractionation.

Organic extractions

None

Single

Normal double

Twice $^{\text {b }}$
${ }^{11} \mathrm{~B} /{ }^{10} \mathrm{~B}{ }^{\mathrm{a}}$

4.0364

4.0350

4.0359

4.0375

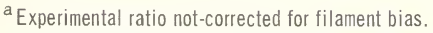 \\ ${ }^{b}$ Carried through the entire extraction procedure twice.}

It was discovered, after a small fraction of the samples gave a ${ }^{11_{B} /{ }^{10} \mathrm{~B}}$ ratio up to $1 \%$ lower than normal, that the amount of $\mathrm{SO}_{2}$ left in the solution is critical. Increasing amounts of $\mathrm{SO}_{2}$ water were added after heating and cooling the acidified fusion. The results are given in table 4 , page 36 . It was found that heating the samples at a higher temperature (approximately $80^{\circ}$ ) and leaving the beaker uncovered, reduced the amount of $\mathrm{SO}_{2}$ sufficiently to give ${ }^{11} \mathrm{~B} /{ }^{1}{ }^{0} \mathrm{~B}$ ratios that were reproducible (see table 5, page 37 ) and agreed with samples that were not extracted.

Synthetic samples, containing all the constituents of the cobalt glass beads and using Argonne II boric acid for the boron, are now being checked by this procedure.

Preliminary results indicate a limit of error of bias of approximately $0.1 \%$ between alternate chemical preparations.

\section{Chromium}

The chromium isotopic composition of approximately seventy mineral samples of different origin are being determined. This will establish constancy of isotopic composition in nature and assist in placing limits on the atomic weight of chromium. The procedure used previously [ref. 1, p. 33] was modified to obtain a better separation of the chromium from the other constituents of the minerals and the sodium from 
the sodium carbonate used in fusion. Approximately seventy samples of fifteen different minerals were carried through the following procedure.

The silicate minerals of chromium were crushed and fused with sodium carbonate. After dissolving in water, hydrogen peroxide was added to insure complete oxidation of chromium. The insoluble material was filtered off and the chromium precipitated as $\mathrm{Cr}(\mathrm{OH})_{3}$ by reducing the chromium with $\mathrm{SO}_{2}$. After igniting the precipitate, it was fused with a small amount of sodium carbonate, dissolved in water, and filtered. The solution was made just acid and heated to decompose the carbonate. Sodium and other cations were removed by passing the solution through a cation exchange column (AG 50-X8). The chromium was reduced with $\mathrm{SO}_{2}$ and precipitated by adding ammonia. The precipitate of $\mathrm{Cr}(\mathrm{OH})_{3}$ was filtered, ignited and weighed. The chromium oxide was dissolved and oxidized in perchloric acid and any insoluble residue was filtered off. The chromium was precipitated with $\mathrm{SO}_{2}$ and ammonia, and filtered. The $\mathrm{Cr}(\mathrm{OH})_{3}$ was dissolved off the filter paper with hot diluted nitric acid and the solution was evaporated to dryness. The chromium was then dissolved in $\mathrm{HNO}_{3}(1+49)$ and hydrogen peroxide added to reduce all the chromium to $\mathrm{Cr}$ (III). After heating to destroy the excess hydrogen peroxide the solutions were diluted with $\mathrm{HNO}_{3}(1+49)$ to give a chromium concentration of $3 \mathrm{mg} / \mathrm{ml}$.

The chromite samples were dissolved in perchloric acid, diluted with water, filtered, and continued as described above starting with the cation exchange column.

The crocoite samples were dissolved in dilute nitric acid by electrodeposition of the lead. The solution was filtered and the chromium was precipitated with $\mathrm{SO}_{2}$ and ammonia. After igniting, the chromium was dissolved in perchloric acid, made just acid with ammonia and continued as described above, starting with the cation exchange column. 
Approximately one-third of the samples did not behave normally in the mass spectrometer. To purify these samples they were oxidized with perchloric acid, and passed through an anion exchange column ( $A G$ 1-X4). After washing the column with water, the chromium was removed with an ammonia-ammonium chloride solution. The chromium was precipitated with $\mathrm{SO}_{2}$, filtered, and dissolved off the filter paper with nitric acid. After evaporating to dryness the chromium was dissolved in $\mathrm{HNO}_{3}(\mathrm{I}+49)$ and diluted to $3 \mathrm{mg} / \mathrm{ml}$. Most of these samples have been behaving normally in the mass spectrometer.

\section{E. Fluorspar}

The Office of Standard Reference Materials has submitted a sample of fluorspar, SRM 79b, for the certification of $\mathrm{CaF}_{2}$. The sample is urgently needed as a standard by the U.S. Customs Bureau for the determination of the import duty of fluorspar imported into the United States. The personinel of this section, having experience in the analyses of this type of material, were assigned the determination of $\mathrm{CaF}_{2}$ even though such an analysis is outside the usual activities of the section.

The prescribed method of analysis of the U.S. Customs Bureau is the J. I. Hoffman method as given on the Certificate of Analyses of Standard Sample 79, Fluorspar. The fluorspar is digested in acetic acid and filtered. After ignition the fluroine is removed from the insoluble calcium fluoride by fuming with perchloric acid and evaporating to dryness. The calcium perchlorate is dissolved in hydrochloric acid and a hydrogen sulfide precipitation is made with the solution acid and ammonical. After removal of excess hydrogen sulfide, the calcium is precipitated with ammonium oxalate and ignited to calcium oxide. From the weight of the calcium oxide the percentage of calcium fluoride in the fluorspar is determined. Since the determination has not been completed the results will be given at a later date. 
F. Lead

A search of the chemical literature has shown that there is a need for a high precision-high accuracy method for lead. A method has been developed which is based on the precipitation of lead chromate with a small excess of potassium dichromate and spectrophotometric determinations of the excess chromate. This method takes advantage of the precise analysis of Standard Reference Material 136b, potassium dichromate, which has been shown to be $99.977 \pm 0.003 \%$ [13]. Results have shown that this method has a precision and accuracy of better than $0.017 \%$. The details of this method will be published elsewhere in the near future.

This method has been applied to the preparation of calibration mixtures of separated lead isotopes for the mass spectrometric determination of absolute abundance ratios. Separated lead isotopes in the form of ${ }^{206} \mathrm{~Pb}\left(\mathrm{NO}_{3}\right)$, and $208 \mathrm{~Pb}$ $\left(\mathrm{NO}_{3}\right)$, were obtained from the Isotopes Division of the Oak Ridge National Laboratory. Emission spectrometric analysis showed that these compounds were of such high purity in regards to elements that would interfere with the assay method that they were used without further purification. The separated isotopes were taken into solution with dilute nitric acid. The lead content of each separated isotope solution was determined by the chromate procedure which was outlined above. The calibration mixtures were then prepared by mixing weighed portions of each separated isotope solution. They were prepared in groups of two to approximate the $208 / 206$ composition of three reference samples of lead which are to be distributed as standard reference materials. These lead reference materials consist of a $92 \%$ radiogenic lead with a $208 / 206$ ratio of about 0.014 , a mixture of a radiogenic lead and a galena lead with a $208 / 206$ ratio of about 1.000 , and a galena lead with a $208 / 206$ ratio of about 2.161 . The calibration mixtures of the separated isotopes will be used to 
determine the absolute abundance ratios of these reference leads. This work is still in progress.

\section{Lead Minerals}

As noted in the introduction, natural variations in isotopic composition can be a source of error in the mass spectrometric determination of atomic weights. This is especially true for lead. The most important source mineral for lead, galena ( $\mathrm{PbS}$ ) has been shown to vary significantly in amounts of $204 \mathrm{~Pb}, 206 \mathrm{~Pb}, 207 \mathrm{~Pb}$, and $208 \mathrm{~Pb}$ because it has been affected by contributions of radiogenic lead. Table 3 shows the calculated atomic weights for three metallic lead samples (from galena) and three samples of galena. The calculated atomic weights have a range of 207.18 to 207.24. These values have not been corrected for possible bias (which is very small based on preliminary work with the calibration standards), but the range is indicative of the variance in the atomic weight of lead. The International Commission on Atomic Weights [14] recommends using the value 207.19 as being representative of the lead "most likely to be encountered in normal laboratory work". They recommend that "atomic weights of widely differing isotopic composition should be calculated from the composition of the masses of the individual species". In view of our experience with "normal" lead, it would seem that, when one is interested in high precision high accuracy lead chemistry, an isotopic analysis is also necessary before a meaningful quantitative statement can be made. Certainly, the stated value of 209.19 without limits leads to false sense of security about the atomic weight of "normal" lead. 
Table 3. Calculated atomic weights for "normal" leads.

\section{Relative Isotopic Composition}

Sample

Atom percent

Atomic weight

$\begin{array}{lccccc} & 204 & 206 & 207 & 208 & \\ \text { Lead Metal - 1 } & 1.427 & 24.153 & 22.084 & 52.336 & 207.216 \\ \text { Lead Metal - 2 } & 1.461 & 23.559 & 22.596 & 52.384 & 207.222 \\ \text { Lead Metal -3 } & 1.463 & 23.629 & 22.518 & 52.390 & 207.221 \\ \text { Galena - 1 } & 1.350 & 26.289 & 21.149 & 51.211 & 207.184 \\ \text { Galena - 2 } & 1.372 & 24.935 & 21.358 & 52.336 & 207.212 \\ \text { Galena - 3 } & 1.539 & 22.531 & 22.642 & 53.289 & 207.241\end{array}$

2. Preparation of Lead from Mineral Samples

The lead from a number of lead minerals was separated and solutions prepared for mass spectrometric analysis. The following procedures were used:

a. Galena (PbS) - A 0.5 to $1.0 \mathrm{gm}$ sample was digested with $20 \mathrm{ml}$ of $(I+1)$ perchloric acid at about $90^{\circ} \mathrm{C}$. (The dilute perchloric acid dissolved the $\mathrm{PbS}$ with evolution of $\mathrm{H}_{2} \mathrm{~S}$ and no evidence of oxidation of sulfide ion was noted.) The resulting solution was diluted to $100 \mathrm{ml}$ with water and $5 \mathrm{ml}$ of nitric acid was added. $\mathrm{PbO}_{2}$ was then electrodeposited onto a platinum gauze anode, weighed and dissolved in a nitric acid-hydrogen peroxide mixture. The resulting solution was evaporated to dryness and residue taken up in $2 \%$ nitric acid so that the final solution contained $25 \mathrm{mg}$ of $\mathrm{Pb}$ per $\mathrm{ml}$. This perchloric acid method of dissolution of galena proved superior to the usual nitric acid method as the sulfide ion was not oxidized so the problems associated with the production of sulfur and occulusion of lead sulfate with the lead dioxide were avoided.

b. Crocoite $\left(\mathrm{PbCrO}_{4}\right)$ - The lead was separated from sparingly soluble lead chromate by covering a 0.5 to $1.0 \mathrm{~g}$ sample with $100 \mathrm{ml}$ of dilute nitric $(1+9)$ and electrodepositing $\mathrm{PbO}_{2}$ on a platinum gauze electrode. (As the lead is 
removed from solution, the lead chromate slowly goes into solution until it is completely dissolved and the lead is completely removed from solution.) The $\mathrm{PbO}_{2}$ was dissolved in nitric acid-hydrogen peroxide, and the $\mathrm{PbO}_{2}$ was redeposited to remove the small amount of chromium that contaminated the first deposit. The resulting $\mathrm{PbO}_{2}$ was dissolved in dilute nitric acid-hydrogen peroxide mixture, evaporated to dryness and taken up in $2 \%$ nitric acid so that the solution for mass spectrometric analysis contained $25 \mathrm{mg} \mathrm{Pb}$ per $\mathrm{ml}$.

c. Pyromorphite $\left[\mathrm{PbClPb}_{4}\left(\mathrm{PO}_{4}\right)_{3}\right]$, wulfenite $\left(\mathrm{PbMOO}_{4}\right)$, and vanadinite $\left[\mathrm{PbClPb}_{4}\left(\mathrm{VU}_{4}\right)_{3}\right]$ - These minerals were also processed by the above procedure except that a third deposition of $\mathrm{PbO}_{2}$ was required to purify the lead.

d. Plattnerite $\left(\mathrm{PbO}_{2}\right)$ and minium $\left(\mathrm{Pb}_{3} \mathrm{O}_{4}\right)$ - These two minerals were dissolved in dilute nitric acid-hydrogen peroxide mixture and the lead was electrodeposited as $\mathrm{PbO}_{2}$ on a platinum gauze anode. Solutions for mass spectrometric analysis were prepared as described above.

3. Archaeological Samples

In cooperation with Dr. Robert H. Brill of the Corning Museum of Glass, the lead and copper from a number of bronze coins from the 1st, 2nd, and 3rd Centuries B.C. and other ancient objects such as a statue, pin, dagger, and bracelet were separated for isotopic analysis.

Since lead varies in isotopic composition depending on the source, the purpose of this work is to correlate these coins and objects to the original mines.

The secondary minerals of copper have also been shown to vary in isotopic composition [7], so the copper was also separated from these ancient coins and objects in the hope of relating them to their source material.

The isotopic analysis of these samples is now in progress. 
G. Plutonium

1. Chemical Standard

The plutonium metal for the replacement of the plutonium chemical standard 949a was prepared at Los Alamos Scientific Laboratory of the University of California, Los Alamos, New Mexico. After purification of the metal, $0.5-0.6 \mathrm{~g}$ samples were weighed to $0.01 \mathrm{mg}$ and sealed in glass tubes. Until sealed all work on the metal was done in a very low oxygen and water atmosphere. Quantitative determination of the impurities, totaling less than $100 \mathrm{ppm}$, as well as the assay of the metal were made at Los Alamos Scientific Laboratory. One member of NBS Section 310.06 collaborated with Los Alamos Scientific Laboratory personnel in the weighing, sealing, and analysis of the samples. After shipment to NBS the samples were packaged in $2 R$ containers, as required by ICC regulation, and the screw caps and joints were coated with plastic "Seal-Stop".

2. Isotopic Standard

The evaluation of the half-life of ${ }^{241} \mathrm{Pu}$ was continued [ref. 1, p. 45; 15, p. 64; 16, p. 71] with the ion exchange separation of americium from the plutonium and the mass spectrometric measurement of the isotopic ratios to determine the decrease of the ${ }^{241} \mathrm{Pu}$ isotope content. In addition, the procedure [ref. 15, p. 65] was modified to separate uranium from plutonium by increasing the volume of 8 N nitric acid to elute both americum and uranium.

(T. J. Murphy, L. A. Machlan, and K. M. Sappenfield) 
A. Boron

A provisional analytical procedure for the isotopic analysis of boron was described in a previous annual report [ref. 1, p. 67]. Subsequent to that report, a number of glasses containing isotopically enriched boron were submitted for certification of both the boron content and the isotopic composition. In order to provide certification it was necessary to evaluate bias parameters, i.e. to ascertain the effects of filament material and impurities on the observed ratio.

A previous report [ref. 1, p. 67] indicated that platinum was superior to tantalum for surface ionization of boron as the $\left(\mathrm{Na}_{2} \mathrm{BO}_{2}\right)^{+}$ion. Old ANL-II solutions (dissolved in 1965) were analyzed and ion currents of $1-2 \times 10^{-11}$ A were obtained with platinum filaments. The experimental ${ }^{1}{ }^{1} \mathrm{~B} /{ }^{10} \mathrm{~B}$ ratios $\mathrm{did}$ not change significantly with time and were slightly lower than the experimental ratios obtained with tantalum filaments. The analytical precision was significantly improved and the signals were generally growing or constant and exhibited good stability. New samples of ANL-II were dissolved and the $\mathrm{B} / \mathrm{Na}$ adjusted to 1 with $\mathrm{Na}_{2} \mathrm{CO}_{3}$. All of these solutions gave ion currents $\left(10^{-13} \mathrm{~A}\right)$ which were erratic and were not suitable even for a rough estimation of the abundance ratio. A brief investigation did not pinpoint the cause or add significantly to an explanation of the phenomenon. In general, this type of behavior is attributed to a physical-chemical effect. Impurities may produce a suppressive or poisoning effect on the ionization process. Removal of contaminant ions by purification chemistry or degassing the sample in the spectrometer, procedures which have been effective for many impurities, did not cause improvement. After several weeks of experimentation and more than 12 new ANL-II solutions, it was necessary to abandon platinum as the filament material and use tantalum. 
In the initial effort to determine the boron content, boron was separated from other constituents of the glass with ion exchange columns but the values produced were discordant. The method of separating boron was changed to an organic extraction technique. ANL-II was used as a sample of known isotopic composition to test and develope the organic extraction procedure. The ANL-II samples were processed in the identical manner prescribed for extraction of boron from cobalt glass which was the most difficult of the glasses to be extracted. The experimental ratios of the first group of extractions were either 4.04 or 3.99 (table 4 ). These ratios were unique and reproducible for a given solution, and the subsequent effort to determine the source of bias required the processing of approximately 100 ANL-II solutions, and more then 300 sample loadings.

Table 4. Organic extraction of ANL-II without control of excess $\mathrm{SO}_{2}$ water.

\section{Experimental}

Sample No.

1

2

3

4

5
${ }^{11} \mathrm{~B} /{ }^{10} \mathrm{~B}$ corrected for ${ }^{17} \mathrm{O}$

4.048

4.043

3.994

3.996

4.047

4.048

3.992

3.991

4.047

4.041

$\mathrm{SO}_{2}$ water, added during digestion to reduce cobalt, was the agent which produced abnormal ratios. In some extractions the volume of $\mathrm{SO}_{2}$ water which was extracted into the 2-ethyl1,3-hexanediol and the $\mathrm{NaOH}$ solution was large enough to neutralize or acidify the $\mathrm{NaOH}$ solution. Table 5 gives the 
experimental ratios for extractions in which $\mathrm{SO}_{2}$ water was not added before digestion but was added in known volumes after digestion and before extraction into the 2-ethyl-1,3hexanediol. The $\mathrm{NaOH}$ solution of sample No. 53, with a pH of 8, was the only extraction to show significant neutralization. This sample yielded less than normal signal intensity during analysis and, based upon titration of the extraction, there was a significant loss of boron. Excess $\mathrm{SO}_{2}$ water was controlled by digesting the solution uncovered and at a temperature of $80^{\circ}-85^{\circ} \mathrm{C}$. The experimental ratios for extractions with this added condition are given in table 6 .

Table 5. Organic extraction of ANL-II with known volume of $\mathrm{SO}_{2}$ water added before extraction into 2-ethyl-1,3-hexanediol.

Volume in $\mathrm{ml}$ of

Sample No.

$39 a$

$43 a$

$46 a$

$54 a$

$47 a$

$53 a$
$\mathrm{SO}_{2}$ water added

0

1.0

2.0

2.0

2.5

3.0
Experimental ${ }^{11} \mathrm{~B} /{ }^{10} \mathrm{~B}$ corrected for ${ }^{17} \mathrm{O}$

4.0336

4.0316

4.0403

4.0412

4.0132

4.0109

4.0111

4.0177

4.0050

4.0045

3.9890

3.9962 
Table 6. Organic extraction of ANL-II with control of excess $\mathrm{SO}_{2}$ water by digesting solution uncovered and at temperature of 80 to $85^{\circ} \mathrm{C}$.

Sample No.

$37 \mathrm{a}$

38a

$44 a$

$45 a$

$46 \mathrm{a}$

\section{Experimental}

${ }^{11} \mathrm{~B} /{ }^{10} \mathrm{~B}$ corrected for ${ }^{17} \mathrm{O}$

4.0352

4.0339

4.0355

4.0362

4.0373

4.0346

4.0344

4.0377

4.0391

4.0347

\section{Average 4.0359}

The two most probable explanations of the abnormal ratios are chemical fractionation during extraction and increased fractionation during mass spectrometric analysis. Evaluation of the degree of chemical fractionation was made using the chemical procedure which controlled excess $\mathrm{SO}_{2}$ water and its extraction into the 2-ethyl-1,3-hexanediol. A single extraction recovers a minimum of $80 \%$ of the boron present, and a second extraction is necessary to increase the recovery to $95 \%$. The ${ }^{1} 1_{B} /{ }^{10} \mathrm{~B}$ ratio for duplicate analysis of a single extraction was 4.0350. Double extraction of the solutions in table 5 gave an average ${ }^{11} \mathrm{~B} / 10_{\mathrm{B}}$ ratio of 4.0359 . After being analyzed, solutions $44 \mathrm{a}$ and $45 \mathrm{a}$ of table 5 were combined and put through the complete extraction chemistry again. It was necessary to combine $44 \mathrm{a}$ and $45 \mathrm{a}$ so that the starting boron weight of $15 \mathrm{mg}$ would be the same for all samples. The final solution, equivalent to a quadruple extraction, gave an average ratio of 4.0375 for duplicate analyses. An ANL-II sample that was dissolved in water with the appropriate volume of $\mathrm{NaOH}$ added and saturated 
with $\mathrm{CO}_{2}$ gave an average ratio of 4.0364 for duplicate analyses. The ratios for a solution without extraction chemistry and solutions with single, double, and quadruple extraction are experimentally identical, and are indicative of the absence of fractionation under the conditions of the experiment. Evaluation of the degree of fractionation under conditions which produce abnormal ratios has not been completed. Increased fractionation or more efficient formation of the $\left(\mathrm{Na}_{2} \mathrm{BO}_{2}\right)^{+}$ion has not been fully evaluated. However, it has been observed that all solutions yielding abnormal ratios were either grey-white or just slightly burned at the end of an analysis. Solutions with ratios of 4.04 also dried greywhite but were charred black during an analysis. Purification chemistry on an abnormal solution with cation and anion exchange columns produced solutions in which the sample turned black during an analysis but the ratio was not affected significantly. The refractory material in abnormal solutions was also removed by reprocessing through the extraction chemistry but the ratio remained unchanged. More work is necessary in this area before conclusions can be made.

ANL-II solutions spiked with known amounts of impurities gave lower experimental ratios than unspiked solutions with identical chemistry. $\mathrm{Ba}, \mathrm{Ca}$, and $\mathrm{Pb}$ were added in 20 and 40 $\mu \mathrm{g}$ samples sizes as impurities. The general effect of adding these impurities was to require 10-20\% higher filament currents to give $1 \times 10^{-12}$ A ion currents. Solutions spiked with calcium gave erratic emission and were, in general, inferior in overall performance. A $2 \mathrm{\mu g}$ sample size of $\mathrm{Sr}$ did not effect the analysis nor was there a detectable $\left(10^{-15} \mathrm{~A}\right)$ strontium signal.

Excessive and/or irregular amounts of sodium in solution with boron was a source of bias. Experimental ratios of solutions with $\mathrm{B} / \mathrm{Na}$ ratios of $1: 1$ or $2: 1$ were nearly identical and did not change significantly at signal intensities of 
$1 \mathrm{x} 10^{-12} \mathrm{~A}$. The experimental ${ }^{11} \mathrm{~B} /{ }^{10} \mathrm{~B}$ ratios of solutions with $\mathrm{B} / \mathrm{Na}$ ratios of $1: 2$ were $1 \%$ higher than solutions of $1: 1$ or $2: 1$. By carefully and slowly heating the filament to produce ion currents less than $1 \times 10^{-12} \mathrm{~A}$, the ${ }^{1{ }^{1}} \mathrm{~B} /{ }^{10} \mathrm{~B}$ ratio was observed changing to 4.08 . The rate of change slowed significantly at this level, and it was possible to make precise measurements. When the $\mathrm{B} / \mathrm{Na}$ ratio is $1: 4$, the $\left(\mathrm{Na}_{2} \mathrm{BO}_{2}\right)^{+}$ion current is completely suppressed at normal filament currents of $1.15-1.30 \mathrm{~A}$. Filament currents of 1.5 A were necessary to obtain $10^{-13} \mathrm{~A}$ ion currents which were usually decaying and difficult to measure precisely.

Sodium carbonate and sodium bicarbonate solutions gave superior overall performance in comparison with the analysis of sodium hydroxide solutions. Emission stability of the hydroxide was poor and analyses were often rejected because of erratic emission. The stability, signal intensity, and rate of decay improved with time and were comparable to carbonate and bicarbonate analyses after 1 hour of heating.

Filaments that were prebaked at 3 A for 1 hour in a vacuum and under a potential field were free of background signals in the mass 85-90 range. Filaments that were not baked gave rubidium ion currents of $10^{-14} \mathrm{~A}$. Strontium ion currents were not detectable at $10^{-15}$ A from either type of filament when operated at 2 A.

The provisional analytical procedure was based upon the concept of quickly ( 15 minutes) generating a $10^{-12}$ A signal and taking data. A series of long-term analyses (2-4 hours) indicated that signal stability and intensity were significantly improved if the $10^{-12} \mathrm{~A}$ ion currents were obtained at a slower rate of heating. The ${ }^{11} \mathrm{~B} /{ }^{1}{ }^{0} \mathrm{~B}$ ratio also exhibited greater stability with time and changed less than $0.5 \%$ over a 4 hour period of heating. The present analytical procedure, evolved from this and other information, is based on a concept of slowly obtaining a total ion current of $1.5 \times 10^{-12} \mathrm{~A}$ over a 
30 minute period and taking data between 32 and 45 minutes after the start of heating.

B. Chromium

A survey is being conducted to determine the limits of natural variation of chromium isotope abundances. Data has been obtained on 40 mineral samples. There is no variation among chromites, but the results on secondary chromium minerals are inconclusive. A number of samples from minerals in which the chromlum is only a trace element give results which are outside the apparent experimental error. However, all of these variations are in the direction to be expected if chemical impurities are present, and, since the purification of these minute samples is extremely difficult, the question of real variation is not yet resolved.

Work on the chromium mineral survey has been temporarily suspended. Analysis of the minerals has been very time consuming because of the excessive rate of sample rejection. Between 30 and $40 \%$ of all analyses attempted were rejected for reasons which include decaying signals, excessive growth, poor stability, signal suppression, and erratic emission.

C. Lead

Accurate determination of the lead isotope compositions of natural samples is of great importance to earth scientists. Geologists, geochemists, and cosmologists use lead isotope measurements to study: the ages of rocks, minerals, meteorites and the earth; the origin, history, and relationships of meteorites and the earth; the nature of fundamental geologic processes, such as vulcanism, mountain building, ore formation, etc.; the chemical composition of the earth's interior; and many other geologic and oceanographic problems.

In studying these problems, investigators have accumulated a vast amount of lead isotope data. Unfortunately, the data fail to meet two important criteria: none of them are absolute, and the precision is frequently too poor for even relative studies. 
The Analytical Mass Spectrometry Section has begun a program for the determination of the absolute isotopic compositions of a number of different lead standards. Upon completion of this study, aliquots of the standards will be distributed to all interested laboratories, so that all future lead isotope studies will be placed on an absolute basis.

A preliminary requirement for the "absolute" study was the development of a more precise method of lead isotope analysis. Recent work has shown that results obtained by the most commonly used method, single-filament $\mathrm{PbS}$, can be affected by such factors as filament material, alkali-ion signals, and $\mathrm{Pb} / \mathrm{NH}_{4} \mathrm{NO}_{3}$ ratio of the mount. These factors may affect the measured $208 \mathrm{~Pb} / 206 \mathrm{~Pb}$ ratio by as much as $2 \%$. No extensive study has been made of the various parameters which might affect the lead tetramethyl gas method or the single-filament $\mathrm{PbC}_{2} \mathrm{O}_{4}$ method, but the poor precisions of these methods also suggest some random bias factors.

A triple-filament method was therefore devised for solidsample lead isotope analysis. The source consists of rheniumribbon sample filaments and a platinum-ribbon ionizing filament. Samples may be in the form of $\mathrm{PbCl}_{2}, \mathrm{~Pb}\left(\mathrm{NO}_{3}\right)_{2}$, or $\mathrm{Pb}(\mathrm{OH})_{2}$; the $\mathrm{Pb}(\mathrm{OH})_{2}$ appears to have the best qualities for analysis. Stable lead ion signals of $6 \times 10^{-11}$ A are consistently obtained with $500 \mu \mathrm{g}$ lead samples, while $20 \mu \mathrm{g}$ samples give stable signals of $4 \times 10^{-13} \mathrm{~A}$. The triple filament method does not have the ionization efficiency of the single-filament $\mathrm{PbS}$ or $\mathrm{PbC}_{2} \mathrm{O}_{4}$ methods, but it has much greater precision. Ten analyses of a reference sample gave $95 \%$ confidence limits (per analysis) of $204 \mathrm{~Pb} / 206 \mathrm{~Pb}=0.054 \%,{ }^{207} \mathrm{~Pb} / 206 \mathrm{~Pb}=0.023 \%$, and ${ }^{208} \mathrm{~Pb} / 206 \mathrm{~Pb}=0.071 \%$.

Table 7 compares the precision of the triple-filament method with some of the best data on replicate analyses of lead samples reported by various workers using different methods. The significantly greater precision of the triplefilament method is probably due to the fact that the results 
appear to be unaflected by any of the variables, such as signal size, sample size, sample composition, time of datataking, or alkali-ion signals, which appear to affect the results of other methods.

Tale 7. Comparison of $95 \%$ confidence limits ( $t a$ ) of best data on replicate lead isotope analyses by various methods.

Imeatigetor and method

Doe et al. (1965), solid PbS single-filament $\mathrm{Re}, 11$ analyses
95\% confidence limits per analysis (in \%) ${ }^{204} \mathrm{~Pb} /{ }^{206} \mathrm{~Pb}$ ${ }^{207} \mathrm{~Pb} /{ }^{206} \mathrm{~Pb}$ ${ }^{208} \mathrm{~Pb} /{ }^{206} \mathrm{~Pb}$

0.22

0.22

0.29

Richards and Cooper (1966),

0.12

0.17

0.22 solid $\mathrm{PbC}_{2} \mathrm{O}_{4}$, single-filament $\mathrm{Re}, 8$ analyses

Kollar et al. (1960), gas

0.24

0.17

0.13

$\left(\mathrm{CH}_{3}\right)_{4} \mathrm{~Pb}, 5$ analyses

This paper, solid $\mathrm{Pb}(\mathrm{OH})_{2}$, triple-

0.054

0.023

0.071

filament $\operatorname{Re}$ (sample) and $\mathrm{Pt}$

(ionizing), 10 analyses

The triple-filament method, because of its greater precision, will probably replace all other methods whenever two conditions can be met: the sample size must be greater than $100 \mu \mathrm{g}$, and an efficient mass spectrometer must be used. The installation of a $\mathrm{z}$ lens in the instruments of this section, which increased the source efficiency by a factor of about 4, was an important step in the evolution of this technique. With samples of less than $100 \mu \mathrm{g}$, the singlefilament $\mathrm{PbS}$ or $\mathrm{PbC}_{2} \mathrm{O}_{4}$ methods would probably be preferable. The lead tetramethyl gas method requires large samples and may very well become obsolete.

A preliminary study of the lead isotope compositions of some secondary lead minerals has been made. The results 
indicate that the geologically recent formation of secondary lead minerals from older lead minerals can occur without significant contamination by rock leads, even when transportation over considerable distances has apparently occurred. This means that the isotopic composition of the lead in secondary minerals may be useful as a tracer in the studies of the oxidation of ore deposits, the groundwater transportation of lead, and the origin and paragenesis of secondary ore deposits.

\section{Plutonium}

The annual analysis of Plutonium Standard 948 was made July 12-13, 1966. The purpose of this series of annual measurements is to accurately determine the half-life of ${ }^{241} \mathrm{Pu}$. Each year a new sampling of the standard is usually dissolved and analyzed with samples dissolved in previous years, but because of the move to Gaithersburg, chemical facilities were not available to prepare a new solution in 1966, and only the old solutions dissolved in 1964 and 1965 were used. The ${ }^{241} \mathrm{Am}$ was removed with an ion exchange column no more than 24 hours before the samples were run. A thermal ionization mass spectrometer with a Z-lens ion source was used, and the increased transmission did not warrent use of an ion multiplier. Each solution was analyzed with sample sizes of 2 and $4 \mu \mathrm{g}$. The calculated half-life as of July 1967 is 14.9 years with an undefined uncertainty.

\section{E. Rubidium}

Sub-samples of one lot of Standard Reference Material (SRM) rubidium were analyzed and were isotopically homogeneous within the analytical limit of error of $0.1 \%$ of the abundance ratio. SRM samples were also compared with the NBS rubidium reference standard and were isotopically homogeneous. SRM samples were analyzed as $\mathrm{RbCl}_{2}$, and the analytical procedure was basically the same as the procedure for $\mathrm{Rb}_{2} \mathrm{SO}_{4}$ [1]. The major difference was the sample-filament temperature necessary 
to produce $10^{-11}$ A of ${ }^{85} \mathrm{Rb}$. Temperatures hot enough to volatilize $\mathrm{Rb}_{2} \mathrm{SO}_{4}$ will deplete the sample-filaments of $\mathrm{RbCl}_{2}$. Analysis of rubidium as the chloride eliminates surface ionization at sample-filament surfaces as a source of bias. Surface ionization at sample filament surfaces (a shortcoming of sulfate analysis which was controlled by placing an upper limit of $0.8 \mathrm{~A}$ on the current) occurred when the filament current was greater than 1 A. The limited number of analyses of $\mathrm{RbCl}_{2}$ indicated that the overall analytical performance of rubidium as the chloride was superior to the analytical performance of rubidium as the sulfate.

F. Uranium

A thermal ionization mass spectrometer with a Z-lens ion source was used to determine the absolute ${ }^{235} \mathrm{U} /{ }^{23}{ }^{8} \mathrm{U}$ ratios of the standards U150 and U050. Samples of known isotopic composition were used to calibrate for instrumental bias. The low-temperature analytical procedure [ref. $\perp, p .55]$ was used for all samples.

The increased transmission of Z-lens optics significantly improves measurement of $10 \mathrm{~W}$ assay $234 \mathrm{U}$ and $236 \mathrm{U}$ and extends the lower limit of the assay range at which precise measurements of these isotopes can be made with a conventional faraday-cage collector from 0.10 to 0.02 atom percent. Ion multipliers are still recommended and are a necessity for precise measurements below 0.02 atom percent. Improvement in ${ }^{235} \mathrm{U} / 238 \mathrm{U}$ measurements is also anticipated because it is now possible to obtain $3-5 \times 10^{-11}$ A ion currents with less chance of overheating and significantly changing the rate of fractionation unique to low-temperature analysis.

(E. J. Catanzaro and E. L. Garner) 
4. PERSONNEL AND ACTIVITIES

A. Personnel Listing

William R. Shields, Section Chief

Joy J. Shoemaker, Secretary

Mass Spectrometry (absolute isotope ratio) --

Ernest L. Garner

Mass Spectrometry (isotope dilution) --

Edward J. Catanzaro

Stoichiometry --

Thomas J. Murphy

Stoichiometry (nuclear materials) --

Lawrence A. Machlan

Separation and Purification --

Keith M. Sappenfield

Design and Fabrication --

William A. Bowman, III

Guest Worker during 1966 --

\section{Takuji Komori}

B. Publications

NOTE: A complete list of all the publications by members of this section is given below. The complete list has been included with the hope that it will aid those who have to do literature searches, and at the same time the titles should define the areas where the various members of the section have some skill.

1. T. J. Murphy, W. S. Clabaugh, and R. Gilchrist, Separation of Iodide, Bromide, and Chloride from One Another and Their Subsequent Determination, J. Res. NBS, 53, 13-18 (1954).

2. R. L. Smith, W. R. Shields, and C. D. Tabor, An Interpolative Method of Assaying $\mathrm{UF}_{6}$ with the Isotopic Mass Spectrometer, GAT-171, AEC Research and Development Report (Declassified), (1956). 
3. L. A. Machlan and J. L. Hague, Photometric Determination of Tungsten in Steel and Titanium Alloys with Dithiol, J. Res. NBS, 59, 415-420 (1957).

4. J. L. Hague and L. A. Machlan, Determination of Titanium, Zirconium, Niobium, and Tantalum in Steels: Separations by Anion-Exchange, J. Res. NBS, 62, 11-19 (1959).

5. J. L. Hague and L. A. Machlan, Determination of Niobium and Tantalum in Titanium-Base Alloys, J. Res. NBS, 62, 53-57 (1959).

6. W. R. Shields, D. N. Craig, and V. H. Dibeler, Absolute Isotopic Abundance Ratio and the Atomic Weight of Silver, J. Am. Chem. Soc., 82, 5033-5036 (1960).

7. E. J. Catanzaro and P. W. Gast, Isotopic Composition of Lead in Pegmatitic Feldspars, Geochim. Cosmochim. Acta, 19, 113-126 (1960).

8. L. A. Machlan, J. L. Hague, and E. J. Meros, Determination of Aluminum in Precipitation Hardening Stainless Steel and High Temperature Alloys, J. Res. NBS, 64A, 181-184 (1960).

9. T. J. Murphy and W. S. Clabaugh, Preparation of Sulfur of High Purity, J. Res. NBS, 64A, 355-358 (1960). 10. T. J. Murphy, W. S. Clabaugh, and R. Gilchrist, Method for the Separation of Titanium, Zirconium, Iron, and Aluminum from One Another and for Their Subsequent Determination, J. Res. NBS, 64A, 535-542 (1960).

11. J. L. Hague and L. A. Machlan, Separation of Hafnium from Zirconium by Anion Exchange, J. Res. NBS, 65A, 75-77 (1961).

12. W. R. Shields, E. L. Garner, and V. H. Dibeler, Absolute Isotopic Abundance of Terrestrial Silver, J. Res. NBS, 66A, $1-3$ (1962).

13. L. A. Machlan and J. L. Hague, Separation of Hafnium from Zirconium and Their Determination: Separation by Anion-Exchange, J. Res. NBS, 66A, 517-520 (1962). 
14. W. R. Shields, T. J. Murphy, E. L. Garner, and V. H. Dibeler, Absolute Isotopic Abundance Ratio and the Atomic Weight of Chlorine, J. Am. Chem. Soc., 84, 1519-1522 (1962).

15. E. J. Catanzaro, Zircon Ages in Southwestern Minnesota, J. Geophys. Res., 68, 2045-2048 (1963).

16. J. L. Kulp, R. Kologlovov, J. Engles, E. J. Catanzaro, H. Neuman, and B. Nilssen, Age of the Tordal, Norway Pegmatite -- A Correction, Geochim. Cosmochim. Acta, $\underline{27}, 847-848$ (1963).

17. J. N. Rosholt, W. R. Shields, and E. L. Garner, Isotope Fractionation of Uranium in Sandstone, Science, 139, No. 3551, 224-226 (1963).

18. W. R. Shields, E. L. Garner, C. E. Hedge, and S. S. Goldich, Survey of $\mathrm{Rb}^{85} / \mathrm{Rb}^{87}$ Ratios in Minerals, J. Geophys. Res., 68, 2331-2334 (1963).

19. P. Lessing and E. J. Catanzaro, $\operatorname{Sr}^{87} / \mathrm{Sr}^{86}$ Ratios in Hawailan Lavas, J. Geophys. Res., 69, 1599-1601 (1964).

20. E. J. Catanzaro and J. L. Kulp, Discordant Zircons from the Little Belt (Montana), Beartooth (Montana), and Santa Catalina (Arizona) Mountains, Geochim. Cosmochim. Acta, 28, 87-124 (1964).

21. J. N. Rosholt, E. N. Harshman, W. R. Shields, and E. L. Garner, Isotopic Fractionation of Uranium Related to Roll Features in Sandstone, Shirley Basin, Wyoming, Economic Geology, 59, 570-585 (1964).

22. J. N. Rosholt, E. L. Garner, and W. R. Shields, Fractionation of Uranium Isotopes and Daughter Products in Weathered Granite and Uranium-Bearing Sandstone, Wind River Basin Region, Wyoming, Annual Review of Geological Survey, 501-B, B84-B87 (1964).

23. W. R. Shields, T. J. Murphy, and E. L. Garner, Absolute Isotopic Abundance Ratio and the Atomic Weight of a Reference Sample of Copper, J. Res. NBS, 68A, 589-592 (1964). 
24. E. J. Catanzaro, T. J. Murphy, E. L. Garner, and W. R. Shields, Absolute Isotopic Abundance Ratio and the Atomic Weight of Bromine, J. Res. NBS, 68A, 593-599 (1964).

25. R. D. Morton and E. J. Catanzaro, Stable Chlorine Isotope Abundances in Apatite from Ødegardens Verk, Norway, Norsk Geologisk Tidsskrift, 44, Part 3, 307-313 (1964).

26. T. J. Murphy and J. K. Taylor, Precise Assay of Copper Using Small Samples, Anal. Chem., 37, 929 (1965).

27. W. R. Shields, S. S. Goldich, E. L. Garner, and T. J. Murphy, Natural Variations in the Abundance Ratio and the Atomic Weight of Copper, J. Geophys. Res., 70, No. 2, 479-491 (1965).

28. J. N. Rosholt, A. P. Butler, E. L. Garner, and W. R. Shields, Isotopic Fractionation of Uranium in Sandstone, Powder River Basin, Wyoming, and Slick Rock District, Colorado, Economic Geology, 60, 199-213 (1965).

29. J. T. Herron, H. M. Rosenstock, and W. R. Shields, Negative Surface Ionization of Complex Molecules, Nature, 206, No. 4984, 611 (1965).

30. W. R. Shields, "Absolute Isotopic Abundance Ratios of ..." by Surface or Thermal Ionization, Paper presented at Thirteenth Annual Conference on Mass Spectrometry and Allied Topics held in St. Louis, May 16-21, 1965.

31. E. J. Catanzaro and T. J. Murphy, Magnesium Isotope Ratios in Natural Samples, J. Geophys. Res., 71, No. 4, 12711274 (1966).

32. W. R. Shields, The Evolution of the Accuracy of Isotopic Analysis by Thermal Ionization from $2 \%$ to $0.02 \%$, Nuclear Materials Management, International Atomic Energy Agency, Vienna, 1966, pp. 737-746.

33. W. R. Shields, T. J. Murphy, E. J. Catanzaro, and E. L. Garner, Absolute Isotopic Abundance Ratios and the Atomic Weight of a Reference Sample of Chromium, J. Res. NBS, 70A, 193-197 (1966). 
34. Analytical Mass Spectrometry Section: Instrumentation and Procedures for Isotopic Analysis, NBS Technical Note 277, Ed. W. R. Shields, (1966).

35. E. J. Catanzaro, T. J. Murphy, E. L. Garner, and W. R. Shields, Absolute Isotopic Abundance Ratios and the Atomic Weight of Magnesium, J. Res. NBS, 70A, 453-458 (1966).

36. E. J. Catanzaro, Correlation of Some Precambrian Rocks and Metamorphic Events in Parts of Wyoming and Montana, The Mountain Geologist, 4, No. 1, 9-21 (1967).

37. E. J. Catanzaro, A Triple-Filament Method for Solid-Sample Lead Isotope Analysis, J. Geophys. Res., 72 , No. 4, 1325-1327 (1967).

C. Talks

1. W. R. Shields, "Standards Program and Calibration", Pennsylvania State University, College Park, Pennsylvania, October 31, 1966.

2. W. R. Shields, "Filament Material and Sample Form", Pennsylvania State University, College Park, Pennsylvania, November $1,1966$.

3. E. J. Catanzaro, "Stable Isotope Variations in Nature", Pennsylvania State University, College Park, Pennsylvania, November 2, 1966.

4. E. J. Catanzaro, "Correlation of Some Precambrian Rocks and Metamorphic Events in Parts of Wyoming and Montana", University of Pennsylvania, Philadelphia, Pennsylvania, May 5, 1967.

5. W. R. Shields, "Hardware for Isotopic Analysis", Atomic Physics Colloquium, NBS, May 25, 1967. 
D. Committee Activities

L. A. Machlan

Member, Chemistry Panel of Interagency Board of Civil Service Examiners

T. J. Murphy

Member, Chemistry Panel of Interagency Board of Civil Service Examiners

Chairman, Committee on Meeting Arrangements, Chemical Society of Washington

Member, Arrangements Committee, IMR Symposium on Trace Characterization

Member, Committee on Annual Report of Atomic Weights, American Chemical Society

Manager, Chemical Society of Washington

Member, Committee on Analytical Reagents of the American Chemical Society 


\section{REFERENCES}

[1] W. R. Shields, Editor, NBS Technical Note 277, (1966).

[2] W. R. Shields, T. J. Murphy, E. I. Garner, and

V. H. Dibeler, "Absolute Isotopic Abundance Ratio and the Atomic Weight of Chlorine", J. Am. Chem. Soc., 84, 1519-1522 (1962).

[3] E. J. Catanzaro, T. J. Murphy, E. L. Garner, and W. R. Shields, "Absolute Isotopic Abundance Ratio and the Atomic Weight of Bromine", J. Res. NBS 68A, 593-599 (1964).

[4] W. R. Shields, T. J. Murphy, E. J. Catanzaro, and E. L. Garner, "Absolute Isotopic Abundance Ratios and the Atomic Weight of a Reference Sample of Chromium", J. Res. NBS, 70A, 193-197 (1966).

[5] W. R. Shields, T. J. Murphy, and E. L. Garner, "Absolut. Isotopic Abundance Ratio and the Atomic Weight of a Reference Sample of Copper", J. Res. NBS, 68A, 589-592 (1964).

[6] E. J. Catanzaro, T. J. Murphy, E. L. Garner, and W. R. Shields, "Absolute Isotopic Abundance Ratios and the Atomic Weight of Magnesium", J. Res. NBS, 70A, 453458 (1966).

[7] W. R. Shields, S. S. Goldich, E. I. Garner, and T. J. Murphy, "Natural Variations in the Abundance Ratio and the Atomic Weight of Copper", J. of Geophys. Res., 70, No. 2, 479-491 (1965).

[8] E. J. Catanzaro and T. J. Murphy, "Magnesium Isotope Ratios in Natural Samples", J. of Geophys. Res., I1, No. 4, 1271-1274 (1966).

[9] COMPTES RENDUS of the Twenty-third Conference of the International Union of Pure and Applied Chemistry, Paris, July 2-9, 1965.

[10] M. R. Hayes and J. Metcalfe, "The Boron - Curcumin Complex in the Determination of Trace Amounts of Boron", Analyst 87, 956-969 (1962). 
[11] J. D. Wolszon, J. R. Hayes, and W. H. Hill, "Applications of Anion Exchange Resins to Determination of Boron", Anal. Chem. 29, 829-832 (1957).

[12] E. J. Agazzi, "Extraction-Flame Photometric Determination of Boron", Anal. Chem. 39, 233-235 (1967).

[13] G. Marinenko and J. K. Taylor, "Precise Coulometric Titrations of Potassium Dichromate", J. Res. NBS 67A, 453-459 (1963).

[14] A. E. Cameron and Edward Wichers, "Report of the International Commission on Atomic Weights (1961)", J.A.C.S. 84, 4175-95 (1962).

[15] 0. Menis, Editor, NBS Technical Note 275, (1965).

[16] 0. Menis, Editor. NBS Technical Note 402. (1966). 



\section{NBS TECHNICAL PUBLICATIONS}

\section{PERIODIGALS}

JOURNAL OF RESEARCH reports $\mathrm{Na}$ tional Bureau of Standards research and development in physics, mathematics, chemistry, and engineering. Comprehensive scientific papers give complete details of the work, including laboratory sata, experimental procedures, and theoretical and nathematical analyses. Illustrated with photographs, drawings, and charts.

Published in three sections, available separately:

\section{Physics and Chemistry}

Papers of interest primarily to scientists working in these fields. This section covers a broad range of physical and chemical research, with major emphasis on standards of physical measurement, fundamental constants, and properties of matter. Issued six times a year. Annual subscription: Domestic, \$5.00; foreign, $\$ 6.00^{*}$.

\section{Mathematics and Mathematical Physics}

Studies and compilations designed mainly for the mathematician and theoretical physicist. Topics in mathematical statistics, theory of experiment design, numerical analysis, theoretical physics and chemistry, logical design and programming of computers and computer systems. Short numerical tables. Issued quarterly. Annual subscription: Domestic, $\$ 2.25$; foreign, $\$ 2.75^{*}$.

\section{Engineering and Instrumentation}

Reporting results of interest chiefly to the engineer and the applied scientist. This section includes many of the new developments in instrumentation resulting from the Bureau's work in physical measurement, data processing, and development of test methods. It will also cover some of the work in acoustics, applied mechanics, building research, and cryogenic engineering. Issued quarterly. Annual subscription: Domestic, $\$ 2.75$; foreign, $\$ 3.50^{*}$.

\section{TECHNICAL NEWS BULLETIN}

The best single source of information concerning the Bureau's research, developmental, cooperative and publication activities, this monthly publication is designed for the industry-oriented individual whose daily work involves intimate contact with science and technology-for engineers, chemists, physicists, research managers, product-development managers, and company executives. Annual subscription: Domestic, \$1.50; foreign, $\$ 2.25^{*}$.

-Difference in price is due to extra cost of foreign mailing.

\section{NONPERIODICALS}

Applied Mathematics Series. tables, manuals, and studies.

Mathematical

Building Science Series. Research results, test methods, and performance criteria of building materials, components, systems, and structures.

Handbooks. Recommended codes of engineering and industrial practice (including safety codes) developed in cooperation with interested industries, professional organizations, and regulatory bodies.

Miscellaneous Publications. Charts, administrative pamphlets, Annual reports of the Bureau, conference reports, bibliographies, etc.

Monographs. Major contributions to the technical literature on various subjects related to the Bureau's scientific and technical activities.

National Standard Reference Data Series. NSRDS provides quantitative data on the physical and chemical properties of materials, compiled from the world's literature and critically evaluated.

Product Standards. Provide requirements for sizes, types, quality and methods for testing various industrial products. These standards are developed cooperatively with interested Government and industry groups and provide the basis for common understanding of product characteristics for both buyers and sellers. Their use is voluntary.

Technical Notes. This series consists of communications and reports (covering both other agency and NBS-sponsored work) of limited or transitory interest.

\section{CLEARINGHOUSE}

The Clearinghouse for Federal Scientific and Technical Information, operated by NBS, supplies unclassified information related to Governmentgenerated science and technology in defense, space, atomic energy, and other national programs. For further information on Clearinghouse services, write:

Clearinghouse

U.S. Department of Commerce Springfield, Virginia 22151

Order NBS publications from:

Superintendent of Documents

Government Printing Office

Washington, D.C. 20402 
U.S. DEPARTMENT OF COMMERCE

WASHINGTON, D.C. 20230

OFFICIAL BUSINESS
FOSTAGE AND FEES PAID

U.8. DEPARTMENT OF COMMERCE. 